\title{
Grassroots journalism in your own backyard: How citizen reporters build hyperlocal communities
}

Jan Lauren Boyles

West Virginia University

Follow this and additional works at: https://researchrepository.wvu.edu/etd

\section{Recommended Citation}

Boyles, Jan Lauren, "Grassroots journalism in your own backyard: How citizen reporters build hyperlocal communities" (2006). Graduate Theses, Dissertations, and Problem Reports. 3226.

https://researchrepository.wvu.edu/etd/3226

This Thesis is protected by copyright and/or related rights. It has been brought to you by the The Research Repository @ WVU with permission from the rights-holder(s). You are free to use this Thesis in any way that is permitted by the copyright and related rights legislation that applies to your use. For other uses you must obtain permission from the rights-holder(s) directly, unless additional rights are indicated by a Creative Commons license in the record and/ or on the work itself. This Thesis has been accepted for inclusion in WVU Graduate Theses, Dissertations, and Problem Reports collection by an authorized administrator of The Research Repository @ WVU. For more information, please contact researchrepository@mail.wvu.edu. 
Grassroots Journalism in Your Own Backyard:

How Citizen Reporters Build Hyperlocal Communities

\title{
Jan Lauren Boyles
}

\author{
Thesis submitted to the \\ P.I. Reed School of Journalism \\ at West Virginia University \\ in partial fulfillment of the requirements \\ for the degree of
}

\author{
Master of Science \\ in \\ Journalism
}
Ralph E. Hanson, Ph.D., Chair
Maryanne Reed, M.S., Dean
John Temple, M.F.A.
Jeffrey Worsham, Ph.D.

School of Journalism

\section{Morgantown, West Virginia \\ 2006}

Keywords: hyperlocal media, citizen journalism, mainstream media, blog Copyright 2006 Jan Boyles 


\author{
ABSTRACT \\ Grassroots Journalism in Your Own Backyard: \\ How Citizen Reporters Build Hyperlocal Communities \\ Jan Lauren Boyles
}

Americans are flocking to the Internet for news and information. However, the majority of online journalism targets a national audience, thereby lacking a proximate focus.

Hyperlocal media sites - online news outlets that form small, virtual communities of citizen reporters to cover real-world, geographic spaces - are multiplying on the web. The sites aspire to bring neighborhood news to the net through the work of citizen journalists.

In order to further investigate the emerging grassroots media phenomenon, the researcher conducted interviews with hyperlocal practitioners. In the pages that follow, the insider perspective behind hyperlocal media will be illumed through the eyes of the pioneers who aim to change the very definition of journalism. 


\section{ACKNOWLEDGEMENTS}

Returning for graduate studies at my alma mater, West Virginia University, ranks among my greatest life blessings. Not only am I lucky enough to engage with others in a vibrant research community; I am also unbelievably fortunate to be surrounded by concerned faculty and staff who care that students are intellectually nourished while internally nurtured.

To that end, I want to extend my deepest gratitude to Dr. Ralph Hanson. Through his steadfast mentorship, the study's research objective evolved and was ultimately strengthened. But beyond the parameters of this project, Dr. Hanson served as a role model - in that his voracious appetite for learning served as an inspiration for me to continue my own academic pursuits. Furthermore, his support of and confidence in this project is unparalleled.

The dedicated members of my thesis committee - Dean Maryanne Reed, Prof. John Temple and Dr. Jeffrey Worsham - provided meaningful feedback toward this study's scope and methodology. Thanks for taking time from your respective schedules to work on this endeavor.

The findings would not have been possible without the insider perspective provided through indepth interviews with hyperlocal practitioners. Mark Potts, Dan Gillmor, Sean Bonner and Barry Parr graciously spared time to share their candid insight into the realm of citizen journalism.

Dr. Diana Knott's guidance through the Institutional Review Board protocol was invaluable. Patiently, Dr. Knott assisted in the completion of all paperwork necessary for involving human subjects in my research. Her contagious, positive spirit and advocacy of my research cannot be thanked enough.

Dr. Terry Wimmer guided this project through its infancy when the research sought to encompass the blogosphere. His preliminary suggestions were instrumental to the research's final outcome.

A heartfelt note of appreciation is also extended to the kind-hearted Martin Hall staff, including Mrs. Pam Hanson and Mrs. Judy Johnson. Both sympathized with my project deadlines and provided so much encouragement (and so much chocolate!) throughout my time at West Virginia.

And thanks to my trusty iBook, which hasn't lost any data or files (well, at least so far...)

Last, but certainly not least of all - I must dearly thank my parents - George and Kay Boyles who provided me with unwavering love, unfailing hope and unending faith. I hope that I've made you proud. Love ya, mean it.

Many thanks to you all. 


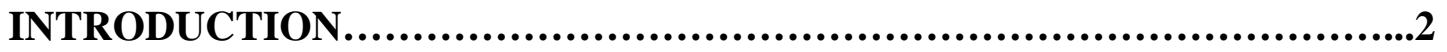

LITERATURE REVIEW ...................................................6

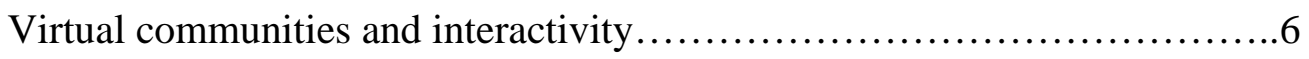

Citizen journalism and hyperlocal media..............................14

Trust and credibility............................................... 18

Citizen journalism experiments...................................22

Old Media on new media.........................................23

RESEARCH QUESTION.....................................................26

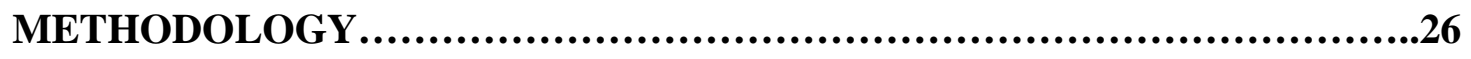

Hyperlocal selection criteria and rationale.............................26

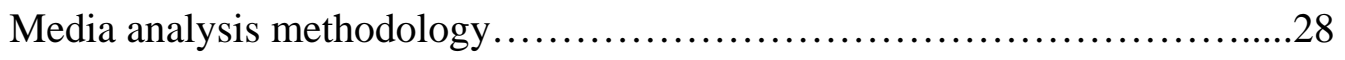

Archival time frame and data collection procedures.....................28

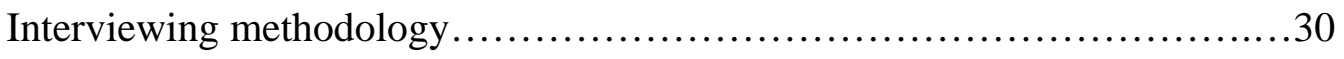

Institutional Review Board approval.................................31

EAST COAST CASE STUDY: BACKFENCE.COM............................32

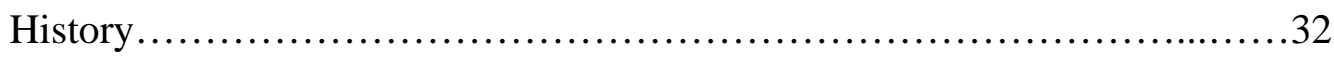

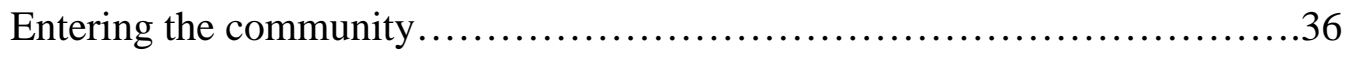




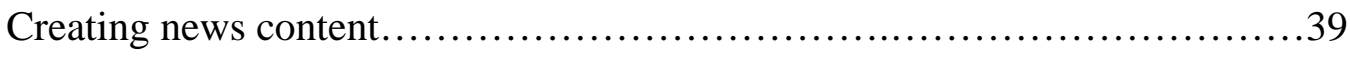

Bethesda, Md..........................................................41

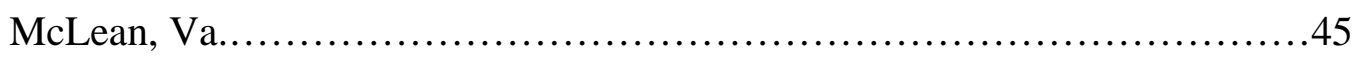

Reston, Va.........................................................49

\section{WEST COAST CASE STUDY: BAYOSPHERE.COM $. . . \ldots \ldots \ldots \ldots \ldots \ldots \ldots \ldots \ldots . . . .52$}

History ....................................................... 52

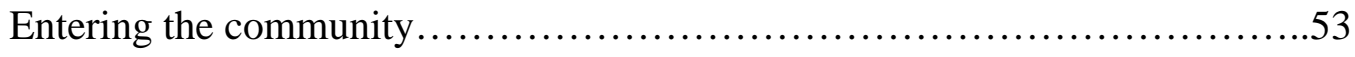

Bayosphere.com's trials..........................................56

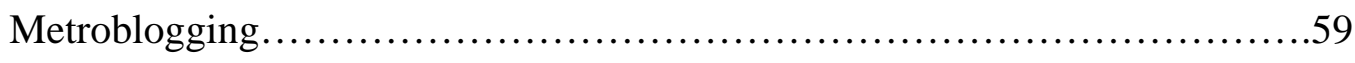

Coastsider.com......................................................63

FINDINGS: HYPERLOCAL MEDIA.......................................66

Building a community..............................................66

Gatekeeping and editorial control....................................72

Future of hyperlocal media.........................................77

CONCLUSION.................................................................84

CODA........................................................................87

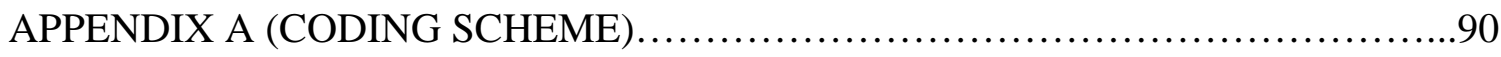

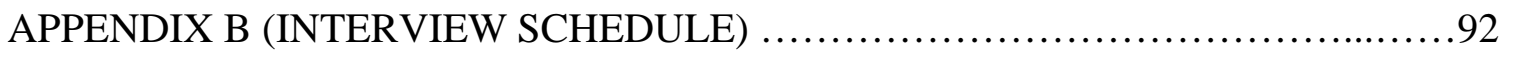

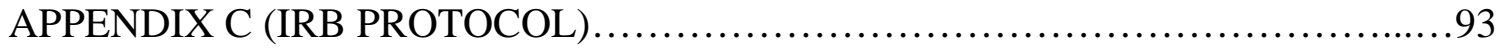


WORKS CITED. 
"It's amazing that the amount of news that happens in the world every day always just exactly fits the newspaper."

- Jerry Seinfeld

“On the Internet, nobody knows you're a dog."

- Peter Steiner cartoon, The New Yorker

"Junk journalism is the evidence of a society that has got at least one thing right - that there should be nobody with the power to dictate where responsible journalism begins."

- Tom Stoppard, Night and Day

"Facts change, but my opinion never does."

- Stephen Colbert, “The Colbert Report”

"It is not necessary to remind you that the fact that your voice is amplified to the degree where it reaches from one end of the country to the other does not confer upon you greater wisdom or understanding than you possessed when your voice reached only from one end of the bar to the other."

- Edward R. Murrow 


\section{INTRODUCTION}

"This population is not made up of customers to whom you must sell, or even constituents to whom you must pander, but of partners on whom you can rely and with whom you can act."

- Douglas Rushkoff

Daily, newsstand purveyors peddle a vast array of printed content. Despite the information plethora, statistics released by the Audit Bureau of Circulations suggest newspaper circulation continues its steady decline. ${ }^{2}$ During the first half of 2004, 50 percent of the country’s 20 largest metropolitan newspapers reported reduced readership. ${ }^{3}$ In short, audiences are brazenly challenging mainstream media's status as information monopolist. ${ }^{4}$

The New York Times publisher Arthur Sulzberger, Jr. suggests the Internet is "the first communication technology to come along in decades that returned people to the written word." ${ }^{5}$ Studies show fervor for net news is justified, in that more than 55 percent of American adults can residentially access the World Wide Web. ${ }^{6}$ Some suggest the

\footnotetext{
${ }^{1}$ Axel Bruns, Gatewatching: Collaborative Online News Production (New York: Peter Lang Press, 2005), 221.

${ }^{2}$ The Associated Press, "Newspaper Circulation Falls Again,” 1 November 2004, [Accessed via Associated Press wire].

${ }^{3}$ Ibid. The Audit Bureau of Circulations' report, on which the AP article is based, encompasses 841 daily and 662 Sunday papers. Four additional metro newspapers - Newsday, the Dallas Morning News, The Chicago Sun-Times and Hoy - were excluded from the sample because of data irregularities. It should be noted the first three aforementioned papers would be considered among the nation's top 20 had they been included in the ABC's findings.

${ }^{4}$ Bruns, Gatewatching, 219.

${ }^{5}$ Arthur Sulzberger, Jr., "Digital Decision Making at The New York Times,” The Harvard International Journal of Press/Politics 6, no. 2 (2001): 98.

${ }^{6}$ John Horrigan et al., “The Internet and Democratic Debate,” Pew Internet \& American Life Project [Accessed online: 27 October 2004], http://www.pewinternet.org/PPF/r/141/report_display.asp.
} 
seemingly insatiable online information boom could be fueled by increasingly prevalent residential dial-up, cable, Digital Subscriber Line (DSL) and wireless-fidelity (wi-fi) Internet services. ${ }^{7}$

A recent Pew Internet \& American Life Project study lends credence to Sulzberger's conjecture. Individuals are not only consuming online content; they are beginning to create their own web portals for news and information. More than 44 percent of Internet users have posted online content. ${ }^{8}$

National media, like The New York Times, dominate the online landscape. From a random digit-dialing telephone survey of 1,510 adults, researchers extrapolated at least 63 million Americans accessed national news online during the 2004 presidential contest. ${ }^{9}$ By contrast, a similar study conducted during the 2000 election cycle indicated only 30 million Americans used the Internet for information gathering. ${ }^{10}$

Therefore, one could likely argue that obtaining national news from the Internet is fairly facile. Net users may encounter difficulty, however, in learning the final score of the cross-town rival's high school basketball game, the location for the next Rotary club meeting or the schedule for the upcoming county fair. Simply stated, as newspaper subscriptions plummet and traffic to online portals multiplies, more Americans are likely missing local news. ${ }^{11}$

\footnotetext{
${ }^{7}$ Ibid.

${ }^{8}$ Amanda Lenhart et al., "Online Activities and Pursuits," Pew Internet \& American Life Project [Accessed online 3 October 2004], http://www.pewinternet.org/PPF/r/113/report_display.asp.

${ }^{9}$ Horrigan et al., “The Internet and Democratic Debate.”

${ }^{10}$ Ibid.

${ }^{11}$ Jennifer Dorroh, “It’s Like Cable News for Your Neighborhood,” American Journalism Review, June/July 2005, [Accessed online 20 September 2005], http://www.ajr.org/article_printable.asp?id=3905.
} 
Founders of start-up hyperlocal media outlets are attempting to remedy the alleged dearth of online local news by formulating websites focused on proximate communities, or simply stated, small online neighborhoods. Pew Internet research suggests, “...many Americans are beginning to use the Internet to intensify their connection to their local community."12 Some portend potential for "glocalization,” or the ability to “expand users' social worlds to faraway people and simultaneously to bind them more deeply to the place where they live.”13

Collaborative news sites form user-driven communities, rather than passive audiences. ${ }^{14}$ Admittedly, the day’s top headlines on hyperlocal sites might not merit front-page coverage in a traditional, printed product. Analogously, colonial newspapers once thought arrival and departure times for shipping lines could be considered news. ${ }^{15}$ Hyperlocals can be further juxtaposed against weekly newspapers, which extensively feature homespun gossip from rural correspondents. ${ }^{16}$

Yet online user-driven communities inhabited by citizen journalists decide which stories warrant coverage. Some hyperlocal media sites have modified the editorial gatekeeping model. In short, participatory news sites are defined by audience involvement. $^{17}$

\footnotetext{
${ }^{12}$ Steven Schild and Kim Oren, "The Party Line Online: An Oligarchy of Opinion on a Public Affairs Listserve,” Journalism \& Communication Monographs 7, no. 1 (2005): 8.

${ }^{13}$ Ibid.

${ }^{14}$ Bruns, Gatewatching, 280.

${ }^{15}$ William Grosvenor Bleyer, Main Currents in the History of American Journalism (Boston: Houghton Mifflin, 1927): 135.

16 Joe Holley, “Weekly, Strongly,” Texas Monthly 25, 12 (1997): 82.

17 Bruns, Gatewatching, 24.
} 
Jay Rosen - a New York University journalism professor, noted new media critic and blogger - describes the emergence of vox populi-generated coverage as a "loss of sovereignty” for professional journalists, as anyone can assemble and publish content. ${ }^{18}$ With weblogs, wikis and web-based cellular phones nearing ubiquity, the ranks of citizen journalists will likely increase exponentially in the years to come. The subsequent study will begin to piece together a primer into the ever evolving and expansive realm of hyperlocal media and citizen journalism.

\footnotetext{
${ }^{18}$ Rebecca MacKinnon, “Blogging, Journalism and Credibility: Battleground and Common Ground,” paper compiled from the Harvard University Conference on Blogging, (2005).
} 


\section{LITERATURE REVIEW}

"We're talking about the beginning of a global conversation really. And that's going to be to everyone's benefit."

- Dan Gillmor ${ }^{19}$

\section{Virtual Communities and Interactivity}

Traditionally, mass media practitioners produce and distribute knowledge. ${ }^{20}$

Hyperlocal media outlets disseminate knowledge through mediated interaction, in that “some technical medium enables information or symbolic content to be transmitted to individuals who are remote in time and space.”21 The "technical medium” for hyperlocal online media - the Internet - actually promotes intermediation, or the creation of a twoway dialogue between senders and receivers, rather than a one-way monologue. ${ }^{22}$ In short, individuals can initiate "many-to-many conversations” as senders or receivers. ${ }^{23}$

These exchanges foster a mutual sense of awareness among individuals aggregated together into a community. Aristotle suggested that manifested in every state is a community, which unites its members through speech, or logos. ${ }^{24}$ His notion of communication as solely face-to-face interaction persisted for nearly two millennia. ${ }^{25}$

${ }^{19}$ Dan Gillmor, interview by author, transcript from tape-recorded telephone interview, 17 January 2006.

${ }^{20}$ Denis McQuail, McQuail’s Mass Communication Theory (London: Sage, 2000), 64.

${ }^{21}$ Ibid.

22 Ibid.

${ }^{23}$ Ibid., 119.

24 Gregory J. Shepherd and Eric W. Rothenbuhler, Communication and Community (New Jersey: Lawrence Erlbaum, 2001), 3.

25 Ibid., 4. 
Thomas Paine agreed that "people could come together in non-state domains to cooperate in their common affairs." ${ }^{26}$

Defining what constitutes a community is difficult, for the places and manners in which community formation has metamorphosed throughout history. ${ }^{27}$ Sociologist James S. Coleman suggested communities are composed of individuals who share both tangible and intangible commonalities. ${ }^{28}$ Subsequent academics, such as educator Sheldon Berman, suggest communities can tie individuals together not only by shared attributes, but also bond members through divergent interests. ${ }^{29}$ Even though group members may share contrasting points of view, they are bounded together because they bear great respect and responsibility for the community as a whole. ${ }^{30}$ Wood and Judris forwarded a four-part definition of community that could be applied to hyperlocal media. The authors assert that "communities:

1. develop a sense of common purpose/interest for which they assume mutual responsibility;

2. acknowledge member interconnectedness;

3. respect individual differences among members;

\footnotetext{
${ }^{26}$ Adrian Little, The Politics of Community (Edinburgh: Edinburgh University Press, 2002), 15.

${ }^{27}$ George S. Wood, Jr. and Juan C. Judris, Conversations on Community Theory (West Lafayette, Indiana: Purdue University Press, 2002), 8.

${ }^{28}$ Ibid., 9-10.

${ }^{29}$ Ibid., 10.

${ }^{30}$ Ibid.
} 
4. commit themselves to the well being of each other and the integrity and wellbeing of the group."31

The authors further clarify their definition, in that a member can act irresponsibly, but still be considered part of the community. Although there is a tendency toward “mutual responsibility,” members do not bear any requisite duty to the community. ${ }^{32}$ However, if all members are apathetic toward the common good, a community is not present. ${ }^{33}$ Wood and Judris posit some of the fiercest community-based battles can surround what constitutes responsible versus irresponsible member conduct - a definitional facet that assuredly applies to the blogosphere and hyperlocal media. ${ }^{34}$ In his work “Neuromancer,” William Gibson coined the term cyberspace. ${ }^{35}$ Online communities, abounding in cyberspace, have altered the textbook definitions of community. Rheingold asserts online virtual communities “catalyze ...more populist kinds of social organizations." ${ }^{36}$ He believed online communities could evolve into "virtual third places" that would bond members of society together through mutual need. $^{37}$

\footnotetext{
31 Ibid., 12.

${ }^{32}$ Ibid., 13.

${ }^{33}$ Ibid.

${ }^{34}$ Ibid. In this study’s context, the blogosphere refers to all user-driven online media, of which hyperlocal media is a subgenre.

35 Suzanne Keller, Community: Pursuing the Dream, Living the Reality (Princeton: Princeton University Press, 2003), 292.

${ }^{36}$ Schild and Oren, “The Party Line Online: An Oligarchy of Opinion on a Public Affairs Listserve,” 8.

${ }^{37}$ Ibid.
} 
In this research, the user groups constitute virtual communities, or clusters of online citizens who share a common purpose. ${ }^{38}$ Anthony Corrado foreshadowed the growth of such communities. His prescient writings predicted virtual communities would not only conduct thorough debate and discourse, but that the technically elite would ultimately circumvent traditional media altogether. ${ }^{39}$ He wrote "neointermediaries would communicate with each other without reliance on traditional gatekeepers of the media." ${ }^{40}$ Empirically, sociologists have examined communities to see how communication affects their respective formations. ${ }^{41}$ Philosophically, academics also question if communication can foster community. ${ }^{42}$

Tönnies pursued this philosophical tendency, asserting that a virtual community’s bonding elements can be viewed through sociological lenses known as gemeinschaft and gesellschaft. The two-part typology proposed by Tönnies mirrors Weber’s traditional versus legal-rational authority construct and Durkheim's mechanical versus organic solidarity model..$^{43}$

\footnotetext{
${ }^{38}$ Shepherd and Rothenbuhler, Communication and Community, 4.

${ }^{39}$ Richard Davis, The Web of Politics (New York: Oxford University Press, 1999), 41.

${ }^{40}$ Ibid.

${ }^{41}$ Shepherd and Rothenbuhler, Communication and Community, 9.

${ }^{42}$ Ibid.

${ }^{43}$ Muriel Mellow, “The Work of Rural Professionals: Doing the Gemeinschaft-Gesellschaft Gavotte,” Rural Sociology 70, no. 1 (2005): 52. Durkheim's typology, influenced by the dawn of industrialization, suggests communities are "integrative institutions," acting as spheres of freedom from unstable economic alliances.

${ }^{43}$ Unlike Aristotle, Durkheim typified the relationship between state and community as highly dynamic.
} 
Roughly translated as “community,” gemeinschaft suggests individuals are as equally dedicated to the greater association as to their own self-interest. ${ }^{44}$ Under this construct, community members are regulated by personal values and mores. ${ }^{45}$ Citizens' commonly shared values are emphasized. ${ }^{46}$ Outside control is not necessary, as individuals possess deep loyalty toward the community. Conversely, gesellschaft, or “society,” proposes that an individual acts in his or her own self-interest, thereby lacking a collective value system with other individuals. ${ }^{47}$

In a pure sociological analysis, hyperlocal media would seemingly parallel the gemeinschaft model. (It should be noted that applied sociologists would argue separation between the two components of the typology is not possible). Researchers analyzing an online bulletin board community based in Milan, Italy uncovered notions of gemeinschaft dominated member interactions. ${ }^{48}$ The researchers proposed that online groups attain a level of interaction, share a common purpose/identity and compose norms/rules for interaction, thereby mirroring gemeinschaft. ${ }^{49}$

Harvard political scientist Pippa Norris has thoroughly studied online communities. She enumerates bonding groups “reinforce close-knit networks among

\footnotetext{
${ }^{44}$ Ferdinand Tönnies, Community and Society: Gemeinschaft und Gesellschaft, ed. Charles P. Loomis (East Lansing: Michigan State University Press, 1957), 7.

${ }^{45}$ Ibid.

${ }^{46}$ Ibid., 10.

${ }^{47}$ Ibid., 7.

${ }^{48}$ Fiorella De Cindio et al., "Community Networks: Rules of Behavior and Social Structure,” The Information Society 19 (2003): 395.

${ }^{49}$ McQuail, McQuail's Mass Communication Theory, 133.
} 
people sharing similar backgrounds and beliefs. ${ }^{50}$ Conversely, she defines bridging groups as those that "function to bring together disparate members of the community." From a random digit-dialing telephone survey and content analysis of threaded Internet discussion boards, Norris uncovered that most online groups instill "ideological homogeneity." ${ }^{\text {52 }}$ She notes interactive groups are more likely to bring like-minded individuals together than foster relationships between diverse community members.

The bonding phenomenon could be attributed to the nature of online group formation. Virtual community membership can be characterized by innate characteristics or adopted behaviors that parallel group dynamics. ${ }^{53}$ Most online discussion forums, including citizen journalist sites, are deeply permeable and lack strict barriers to entry. ${ }^{54}$

To be truly considered a virtual community, exchanges must possess a high level of interactivity. Rafaeli suggests interactivity occurs as a "natural attribute of face to face communication. ${ }^{, 55}$ But in the electronic world, interactivity requires extensive back and forth communication in the absence of a physical presence. As Bruns ironically suggests, such communication "offers the solitariness of an embodied human being sitting in front of a screen, and it offers a new space of community." ${ }^{, 56}$ Rafaeli writes that "interactivity

\footnotetext{
${ }^{50}$ Pippa Norris, “The Bridging and Bonding Role of Online Communities,” The Harvard International Journal of Press/Politics 7, no. 3 (2002): 3-4.

${ }^{51}$ Ibid.

${ }^{52}$ Ibid.

53 Little, The Politics of Community, 4-5.

${ }^{54}$ Norris, “The Bridging and Bonding Role of Online Communities,” 3-4.

${ }^{55}$ Sheizaf Rafaeli, Interactivity: From New Media to Communication (Beverly Hills: Sage, 1988), 110.

${ }^{56}$ Bruns, Gatewatching, 172.
} 
requires a thread of messages; i.e., a chain of interrelated messages. ${ }^{, 57}$ He further clarifies that interactivity can only be achieved if subsequent online messages reference earlier postings. ${ }^{58}$

A study conducted by media scholar Newhagen analyzed the level of interactivity contained in e-mail messages sent to msnbc.com. ${ }^{59}$ Even though nearly 650 Internet users sent electronic responses regarding one "NBC Nightly News” segment, the messages were not read. Using Rafaeli's definition, Newhagen concluded interactivity is manifested by a two-way information flow. Therefore, the one-way e-mail exchanges did not qualify as truly interactive communication. ${ }^{60}$ Newhagen cites the messages must create an ongoing dialogue between senders and receivers to be declared interactive.

Citizen journalist forums enhance interactivity and provide a feedback loop through readership postings. ${ }^{61}$ Unlike "mainstream media” or MSM websites, citizen journalists are encouraged and often required to provide feedback, creating a conversation referencing earlier posts. So rather than a typical journalistic monologue, hyperlocal sites facilitate an ongoing conversation between virtual communities. ${ }^{62}$

\footnotetext{
${ }^{57}$ Tanjev Schultz, "Interactive Options in Online Journalism: A Content Analysis of 100 U.S. Newspapers,” Journal of Computer-Mediated Communication 5, no. 1 (1999): 1.

${ }^{58}$ Rafaeli, Interactivity, 111.

${ }^{59}$ John E. Newhagen, John W. Cordes and Mark R. Levy, "Nightly@nbc.com: Audience scope and the perception of interactivity in viewer mail on the Internet," University of Maryland research [Accessed online 1 December 2004], http://jnews.umd.edu/johnen/research/nbc.htm.

${ }^{60}$ Ibid.

${ }^{61}$ Neal Conan, “Blogging: A Web Diary Tour,” Talk of the Nation, NPR, 21 June 2004.

${ }^{62}$ Dan Gillmor, We the Media: Grassroots Journalism for the People, by the People (CA: O’Reilly Media, 2004), 29.
} 
Academics suggest blogs and hyperlocal media sites redefine the traditional sender/receiver communication model.

Historical parallels could be drawn to colonial media. Eager to ascertain additional information about the nation's fledgling government, settlers would discuss the latest developments in town taverns. ${ }^{63}$ Tavern owners would tack "official documents, jury lists, public notices...to the tavern's wall along with other news items and advertising notices. ${ }^{64}$ Road-weary travelers could not only rest at the gathering halls, but could exchange news and gossip.

The country’s first newspaper, Publick Occurrences, contained a first edition with a blank final page, which could perhaps be considered the nation's first hyperlocal medium. The omitted news content could not be considered a printer's mistake. Editor Benjamin Harris explained he left the eighth page without type "so the reader could add his own news items before passing it on." ${ }^{65}$ In short, news has evolved from postings on a communal tavern wall to postings on Internet portals for all to see. ${ }^{66}$ But unlike traditional printed products, online stories are no longer "fixed or completed at the time of publication.”67 As users modify postings, the tavern wall metamorphoses before our eyes.

\footnotetext{
${ }^{63}$ Richard L. Merritt, "Public Opinion in Colonial America: Content-Analyzing the Colonial Press,” The Public Opinion Quarterly 27, no. 4 (1963): 365.

${ }^{64}$ Ibid.

${ }^{65}$ Pablo J. Boczkowski, Digitizing the News (MA: The MIT Press, 2004), 141.

${ }^{66}$ Gillmor, We the Media, 30.

${ }^{67}$ Bruns, Gatewatching, 53.
} 


\section{Citizen Journalism and Hyperlocal Media}

"These days, you just have to be in the wrong place at the right time, and you too can cover the news."

- Jonathan Klein, president, $C N N^{68}$

Presciently, McQuail heralded the import of user-driven content. He wrote, “The boundaries between publisher, producer, distributor, consumer and reviewer of the content are blurring. ${ }^{\text {} 99}$ In actuality, individuals can act as both a media producer and consumer, leading one researcher to coin a more appropriate label for citizen journalists: prosumers. ${ }^{70}$ Henig affirms the convergence, stating that citizen journalism encompasses "the creation of blogs and unedited news that allow users to write/post their own content., ${ }^{, 71}$ She differentiates citizen journalism from participatory journalism, which is defined as "the move of established newspapers and news sites to solicit and publish materials, such as photos or personal accounts, from their readers." ${ }^{\text {72 }}$

Participatory journalism, Henig contends, is far from revolutionary. The craft of journalism has been defined as a "reporter's conviction that life is a confrontation with the world outside," Schudson writes. ${ }^{73}$ "The job is to penetrate, to get beyond

\footnotetext{
68 Samantha Henig, “Citizens, Participants and Reporters,” Columbia Journalism Review Daily, [Accessed online 8 July 2005], http://www.cjrdaily.org/politics/citizens_participants_and_repo.php.

${ }^{69}$ McQuail, McQuail’s Mass Communication Theory, 120.

${ }^{70}$ Bruns, Gatewatching, 23.

${ }^{71}$ Henig, “Citizens, Participants and Reporters."

${ }^{72}$ Ibid.

${ }^{73}$ Michael Schudson, The Power of News (Cambridge: Harvard University Press, 1995), 103.
} 
appearances, to find the facts that make the meanings," he continues. ${ }^{74}$ Ever since the advent and proliferation of inexpensive communication technology, eyewitnesses have shared written, audio and video accounts with mass audiences. In this light, Abraham Zapruder's amateur Kennedy assassination footage could be construed as participatory journalism. ${ }^{75}$ It should be noted that the nation's first colonial journalists hardly labeled themselves as reporters, as the Revolutionary era newspaper publishers also printed books, almanacs, pamphlets, lottery tickets and legal forms. ${ }^{76}$ Similarly, today’s citizen journalists neither toil in newsrooms, nor call themselves reporters.

In colonial times, finding a mouthpiece for idea dissemination was not simple, the literature suggests. Operated under elite control, the colonial printing presses emerged as political organs for ideological, opining Federalists. ${ }^{77}$ Some pamphleteers, like Thomas Paine, effectively bypassed the media and brought revolutionary ideas directly to the American public. ${ }^{78}$ For today's American citizen journalists, however, the barriers to entry are low. As previously stated, the emergence of heightened citizen journalism can be attributed to the following alterations in the modern media landscape:

\section{Technological advances}

Thousands of citizens are equipped to be reporters and photojournalists in the field, if necessary. ${ }^{79}$ Revolutionary open source software enables individuals to easily

\footnotetext{
${ }^{74}$ Ibid.

${ }^{75}$ Eric Weiner, “Citizens Journalists at the Point of Breaking News.” NPR, 12 August 2005.

${ }^{76}$ Merritt, “Public Opinion in Colonial America,” 365.

${ }^{77}$ Ibid.

${ }^{78}$ Ibid.

${ }^{79}$ Gillmor, We the Media, 162.
} 
post text and photos to the web. ${ }^{80}$ Therefore, bystanders touched by the deadly tsunami's ravages in Southeast Asia blogged detailed accounts of the deadly quake and its aftermath. ${ }^{81}$ Armed with laptops and digital cameras, individuals without any proper journalistic training trudged through the high waters and into the reporting realm, often scooping Western news reporters. ${ }^{82}$ Photos snapped with mobile telephones after the bombings aboard London's Underground carriages provided portraits of the devastation scenes that were not accessible to credentialed newsmen. ${ }^{83}$ From inconceivable scenes of sorrow and suffering, including Hurricanes Katrina and Rita, many media analysts have voiced renewed confidence in the legitimacy of participatory journalism.

\section{Newsgathering practices}

As an integral element of newsgathering operations, MSM outlets are increasingly seeking citizen journalism submissions. As previously highlighted, the mass media once had monopolistic control over content distribution, for only media behemoths could effectively and economically carry messages simultaneously across expansive distances. Today, citizens are no longer merely urged to call the local television newsroom if they see news happening; now media organizations issue clarion calls for submissions of the news itself.

\section{Financial Limitations}

\footnotetext{
${ }^{80}$ Bruns, Gatewatching, 23.

${ }^{81}$ Jonathan Schwartz, “Blogs Provide Raw Details from Disaster Scene,” The New York Times, 27 December 2004, sec. A, p. 17.

${ }^{82}$ Ibid.

${ }^{83}$ Dan Sabbagh, “Atrocity Brings Glimpse of the Citizen Journalist,” The Times of London, 15 July 2005.
} 
Cash-strapped news organizations are often stretched so thin with manpower and financial resources that citizen journalists can assist in covering ground. ${ }^{84}$ Budgetconscious television stations are beginning to educate “citizen newsgathers.”85 Nashville’s WKRN-TV, for example, conducted a camera training session last spring for 20 local bloggers. ${ }^{86}$ The ABC affiliate taught the citizen journalists how to provide pan and tilt angles - and most importantly - how to keep the camera steady when covering breaking news action. ${ }^{87}$ Current, a cable news network launched with significant financial support from former U.S. Vice President Al Gore, vows that 25 percent of its programming stems from “viewer-created content” submitted by its target demographic audience, 18-to-34-year-olds. ${ }^{88}$

Mainstream media moguls are cautiously embracing the blogosphere, too. Interactivity for seemingly hegemonic networks ranges from blogs for reporters to establishing venues for reader/viewer participation. ${ }^{89}$ In fall 2005, CBS News expanded its Internet news portal by offering an ombudsman-like blog - CBS Public Eye - which features input from the network's news anchors and citizen journalists. ${ }^{90}$ In addition to its

\footnotetext{
${ }^{84}$ Dorroh, “It’s Like Cable News for Your Neighborhood.”

${ }^{85}$ Allison Romano, “Why Everybody is a Reporter: Citizen Journalists Go Mainstream,” Broadcasting \& Cable, 22 August 2005.

${ }^{86}$ Ibid.

${ }^{87}$ Ibid.

${ }^{88}$ Ibid.

${ }^{89}$ Katharine Q. Seelye, "Why Newspapers are Betting On Audience Participation,” The New York Times, 4 July 2005, sec. C, p. 1.

${ }^{90}$ CBS News, “CBS News Unveils Web Strategy,” 12 July 2005, http://www.cbsnews.com/stories/2005/07/12/entertainment/main708433.shtml?CMP=ILC-SearchStories.
} 
new premium broadband service, CNN Pipeline, the network unveiled anchor-driven blogs and revamped citizen journalism features on its site. The broadcast outlet has already embraced the blogosphere with daily "citizen journalist” segments during its late afternoon news program “The Situation Room."91

The next interactive stage beyond blogging - wikis - expands the notion of user interactivity. Wikis allow any user to edit a site’s content at any time, moving citizen journalism from an individual activity to a group one. ${ }^{92}$ Sites, such as wikipedia.org, and its recent beta, wikinews.org, invite users to completely rewrite the site’s news stories. In its embryonic stages, wikipedia required users to submit posts to a site editor. In the site’s first two years, only 12 entries were submitted. ${ }^{93}$ However, once the editorial gates were removed, millions of entries joined the site's ranks.

In mid-2005, Los Angeles Times editorial writers toyed with the technology by posting a wikitorial - an experimental online editorial - for readers to review and edit. However, the newspaper's webmaster was forced to remove the interactive feature because "a few readers were flooding the site with inappropriate material." ${ }^{94}$ Individuals replaced an editorial on Iraq with epithets and pornography. ${ }^{95}$

\section{Trust and Credibility}

\footnotetext{
91 Rebecca Dana, “Blog Chicks Boot Up on Blitzer,” New York Observer, 28 September 2005.

${ }^{92}$ Gillmor, We the Media, 32.

93 Bruns, Gatewatching, 109.

${ }^{94}$ Los Angeles Times, “Where’s the Wikitorial?” 17 July 2005, http://www.latimes.com/news/opinion/editorials/la-wiki-splash,0,1349109.story.

${ }^{95}$ Fred Brown, “Citizen Journalism is not Professional Journalism,” Quill 93, no. 6 (2005): 42.
} 
"Instead of being a gatekeeper, telling people that what's important to them 'isn't news,' we're just opening up the gates and letting people come on in."

- Mary Lou Fulton, publisher, The Northwest Voice ${ }^{96}$

As evidenced with the wikitorial experiment, news organizations can still serve as gatekeepers with citizen-driven words and images. Despite the brave new world of audience interaction, McQuail contends message recipients will demand editorial functioning. ${ }^{97}$

On most hyperlocal sites, individuals - titled editors, moderators and information guides - filter salient information for their respective audiences. ${ }^{98}$ Yet Bruns suggests the notion of media gatekeepers is an antiquated one. He defines gatekeepers as those who "screen information with the clear aim of limiting the range of material passing through the gate in order to address the needs of the publishing organization for which they work."99 In fact, he suggests future journalists will act as librarians in that "they will acquire the broadest knowledge possible of their field in order to be able to point library users in the right direction, but they cannot and do not attempt to limit a user's access to all the other works in the overall library."100 In short, librarians "endorse content rather than guard the door."101 Just as a sole librarian cannot gather all pertinent research

\footnotetext{
${ }^{96}$ Mark Glaser, “The New Voices: Hyperlocal Citizen Media Sites Want You (to Write)!” USC Annenberg Online Journalism Review, 17 November 2004, [Accessed online 21 December 2005], http://ojr.org/ojr/glaser/1098833871.php.

${ }^{97}$ McQuail, McQuail’s Mass Communication Theory, 120.

98 Bruns, Gatewatching, 11.

${ }^{99}$ Ibid., 16.

100 Ibid.

${ }^{101}$ Ibid., 18.
} 
materials, Bruns envisions communities in which all users will be encouraged to seek and filter information. $^{102}$

Therefore, Bruns offers a new entry into the technical lexicon: gatewatching, or "the observation of the outpost and output gates of new publications and other sources, in order to identify important material as it becomes available.»103

Yet even if news could be aggregated and presented independent of journalistic control, as experiments like Google News suggest, individuals will likely continue to turn to journalists for “indexing and interpretation,” Schudson portended. ${ }^{104}$ Gatekeepers lend contextual analysis to events, while assisting readers through an information deluge that would otherwise confound a media consumer. ${ }^{105}$

Nevertheless, some political scientists, computer scientists and journalists are questioning the caliber and depth of online debate. Without professional journalistic standards, some media scholars are wary of independent, user-driven information. ${ }^{106}$ In his excoriating new media critique, Macht writes, “The web has a tendency to loosen the editorial reins.”107 Many reporters dismiss bloggers and citizen journalists as industry aspirants who evade fact checking. Some writers hypothesize that most postings are

\footnotetext{
102 Ibid., 17.

103 Ibid.

${ }^{104}$ Schudson, The Power of News, 2.

105 Bruns, Gatewatching, 19.

106 Thomas J. Johnson, and Barbara K. Kaye, "Cruising is Believing: Comparing Internet and Traditional Sources on Media Credibility Measures,” Journalism \& Mass Communication Quarterly 75, no. 2 (1998): 327.

107 Joshua Macht, “New Medium, Old Rules; The On-Line Editor Comes of Age,” The Harvard International Journal of Press/Politics 6, no. 1 (2001): 130.
} 
stream-of-consciousness rants and "unreflective opinion.”108 As a result, the American public has started to question press trustworthiness.

Trust can be defined as “an attitude of confidence, reliance and approval placed in persons and institutions.”109 Trustworthiness is developed through direct contact with the media and "is based upon consistency of action."110 Americans are not merely questioning the veracity of online media, but express concern over MSM's truthfulness. In a study conducted by the National Opinion Research Center, only 11 percent of Americans expressed “extreme faith” in media. ${ }^{111}$ Nearly one-fifth of those surveyed “deeply distrust the news media.”112 Mistakes, whether intentional or accidental, erode confidence in the media’s unique position as government watchdog and information disseminator. $^{113}$

Johnson and Kaye have conducted numerous studies examining public perceptions of online media credibility. The pair operationally defines online media trustworthiness as the "degree to which politically-interested web users judge information on the Internet to be believable, fair, accurate and in-depth.”"114

\footnotetext{
${ }^{108}$ Yuval Levin, “Politics After the Internet,” Public Interest 149 (2002): 91.

${ }^{109}$ Stephen Klaidman and Tom L. Beauchamp, The Virtuous Journalist (New York: Oxford University Press, 1987), 155.

${ }^{110}$ Ibid., 176.

${ }^{111}$ Johnson and Kaye, “Cruising is Believing?” 326.

${ }^{112}$ Ibid.

${ }^{113}$ Klaidman and Beauchamp, The Virtuous Journalist, 176.

${ }^{114}$ Johnson and Kaye, “Cruising is Believing?” 325.
} 
Highly educated, wealthy men expressed the greatest cynicism toward Internet credibility. ${ }^{115}$ On the contrary, young Internet users have demonstrated the strongest confidence in online media. In one study, a college professor fabricated a website for a local Congressional candidate. ${ }^{116}$ He asked 134 college undergraduates to judge the credibility of the pseudo-site. ${ }^{117}$ More than 75 percent of young students polled considered the website more trustworthy than local television news. ${ }^{118}$

Wonkette.com editor Ana Marie Cox told National Public Radio about her role as a blogger. "I try to distance myself from real reporting as much as possible,” Cox said. "I don’t want the burden of having to, like, be right all the time."119 If citizen journalists share Cox's viewpoint, the craft of journalism could be facing a daunting paradigm shift toward user-driven content that may not foster trust.

\section{Citizen Journalism Experiments}

"If modern American journalism has been a lecture, it's evolving into something that incorporates a conversation and a seminar."

- Dan Gillmor ${ }^{120}$

Despite lingering questions about the medium’s trustworthiness, some MSM organizations are jumping headlong into the waters of hyperlocal media. The primary

\footnotetext{
${ }^{115}$ Ibid.

${ }^{116}$ Ibid., 327.

${ }^{117}$ Ibid.

${ }^{118}$ Ibid.

${ }^{119}$ Conan, "Blogging: A Web Diary Tour.” Talk of the Nation.

${ }^{120}$ Bruns, Gatewatching, 119.
} 
difference between traditional and hyperlocal media is audience participation, Bruns argues. $^{121}$

The Greensboro News \& Record likely ranks as home to the nation's most ambitious mass media/grassroots journalism experiment. The hyperlocal outlet was borne of one reporter's frustration with a source. When confronted about a controversial breaking news story, a local politician refused to talk on the record with a News \& Record journalist. Instead, the politico wrote his side of the story and posted it on his blog, thereby scooping his hometown newspaper. ${ }^{122}$ Critics say the high-tech implementation has succeeded in Greensboro because the town had a vibrant online community before the News \& Record entry into the blogosphere. ${ }^{123}$ The paper hopes to create a "virtual town square” of online debate and discussion. ${ }^{124}$

On the other side of the world, OhMyNews launched five years ago. ${ }^{125}$ Founded by South Korean Oh Yeon Ho, nearly 70 percent of the website's copy is submitted from the organization's 38,000 citizen reporters. ${ }^{126}$

But not all experiments have matched OhMyNews’ success. Blogs posted on the Lawrence (Kansas) Journal World's website only attracted 12 contributors described as “local people who enjoyed being at the center of a spirited debate.”127

121 Ibid.

${ }^{122}$ Seelye, "Why Newspapers are Betting On Audience Participation.”

${ }^{123}$ Ibid.

${ }^{124}$ Ibid.

${ }^{125}$ Donald McIntyre and Yooseung Kim, “The People’s News Source,” Time 165, 23 (2005): 42.

${ }^{126}$ Ibid.

127 Stephen Quinn, The Fundamentals of Multimedia Reporting (New York: Focal Press, 2006), 115. 
Other citizen journalist exemplars include: Bakersfield, California’s Northwest Voice, Northwestern University’s GoSkokie!, University of Missouri’s MyMissourian and Washington, D.C.’s Backfence.com.

\section{Old Media on New Media}

Clearly, the Internet heightens interactivity, as anyone with a modem and computer can start or moderate a conversation. ${ }^{128}$ Journalists, already challenged to construct compelling narratives to engage a fragmented and vanishing audience, must now contemplate that potential readers may purposively evade traditional media content. Researchers believe trepidation regarding the citizen journalism realm has not fully materialized among professional journalists. Most Americans currently use such news sites to merely supplement information garnered from MSM, such as newspapers or television. ${ }^{129}$ According to Pew study respondents, only 6 percent of adults surveyed cited complete reliance upon the Internet for news. ${ }^{130}$

Academically, few have studied how hyperlocal authors create news on their online portals. Yet thousands of print journalists have been penning more bylined, anecdotal articles on the citizen journalist movement, drawing attention to both its content and its influence. Rosen believes citizen reporters exemplify an "extremely democratic form of journalism." ${ }^{\text {131 }}$ He predicts a "power shift from the producers of media to the people formerly known as the audience.”132

\footnotetext{
${ }^{128}$ Gillmor, We the Media, 45.

${ }^{129}$ Marcel Boogers and Gerrit Voerman, "Surfing Citizens and Floating Voters: Results of an Online Survey of Visitors to Political Web Sites during the Dutch 2002 General Elections,” Information Polity 8, no. 1 (2003): 22.

${ }^{130}$ Horrigan, "The Internet and Democratic Debate.”

${ }^{131}$ Gillmor, We the Media, 29.
} 
Citizen journalism has yet to evolve into an egalitarian information medium, as not all online users participate. Despite the promise of deliberative democracy, millions of Americans still lack residential Internet access (particularly high speed service), making hyperlocal participation difficult. Furthermore, as evidenced in the literature, online communities reportedly "bond” like-minded members together. As a result, many online novices wishing to join the chorus might feel intimidated to post their divergent musings, encountering a “spiral of silence.”"133

But at a time when traditional media are losing market share, national outlets are dominating the discussion and debate taverns are disappearing, many believe hyperlocal media sites could become the new public squares. ${ }^{134}$ As history contemplates journalism’s future, citizen journalists are still reporting just a mouse click, or rather clique - away.

\footnotetext{
${ }^{132}$ MacKinnon, “Blogging, Journalism and Credibility: Battleground and Common Ground.”

133 This online behavior could exemplify the "spiral of silence" theory. In her work, Spiral of Silence: Public Opinion - Our Social Skin (Chicago: University of Chicago, 1984), German social theorist Elisabeth Noelle-Neumann suggests opinions are suppressed if the ideas run contrary to the majority's viewpoint.

${ }^{134}$ Matthew Klam, “Fear and Laptops on the Campaign Trail,” The New York Times Magazine, 26 September 2004, 45.
} 


\section{RESEARCH QUESTION}

$\mathrm{RQ}_{1}$ : How do hyperlocal media sites foster and build communities?

\section{METHODOLOGY}

To examine hyperlocal media, the researcher performed a case study of two hyperlocal hotbeds: Washington, D.C. and San Francisco. The academic investigation featured an informal, low-level media content examination and in-depth interviews.

\section{Hyperlocal Selection Criteria and Rationale}

In this study's context, a hyperlocal site is defined as a small, virtual community that binds its members together - not because of ideology or interest - but by proximity. In short, the hyperlocal users share a geographic space (typically a bedroom community or suburb outside a metropolitan area) as well as a virtual one.

Due to the blogosphere's embryonic nature, this study provides an emergent, exploratory glance into the realm of hyperlocal media. The researcher neither examined the medium's effects, nor any established causality of the elements embodied therein. Rather, the primary investigator sought to uncover the hyperlocal practitioners' insider perspective.

In this light, the researcher acknowledges the aforementioned case study approach does not lend itself toward generalizable data. It should be noted that as the web lacks a definitive listing of hyperlocal sites to constitute an independent sampling frame, the researcher did not have the capacity to randomly select portals for analysis. Nevertheless, academic rigor is clearly present in the study's findings, as the researcher triangulated 
several qualitative methodologies. Therefore, the subsequent research will forward a detailed account of grassroots citizen media from the pioneers’ perspective.

Two hyperlocals - backfence.com and bayosphere.com - were chosen for study. Obviously, the two sites embody geographic diversity, allowing for new media exploration on the nation's two coasts. In addition, each site featured a different profit structure. Furthermore, both hyperlocal communities rose to prominence in complex and vibrant mainstream media markets. But most distinctively, the sites ultimately achieved varying degrees of relative success as defined by the site's proprietors.

Backfence.com encompasses a trio of hyperlocal sites based in Washington, D.C., serving Bethesda, Md.; McLean, Va.; and Reston, Va., respectively. ${ }^{135}$ The for-profit, virtual communities surrounding the nation's capital are owned by Backfence, Inc., and are controlled by an advisory board. In October 2005, the citizens' media company received a \$3 million capital infusion from SAS Investors and Omidyar Network. ${ }^{136}$ Backfence's corporate structure and its for-profit business plan separate the three sites from other non-profit hyperlocals.

(As a caveat to the following research, it should be noted that as of this writing for-profit hyperlocals, such as New West - a new citizen journalism outfit in the Rockies, are blossoming exponentially on the net. Backfence.com, however, is perceived by many as the trailblazer for establishing a for-profit business model for hyperlocal media).

In 2006, backfence.com will expand to seven communities surrounding Washington, D.C., and 10 additional U.S. cities. As of early 2006, the site does not have

135 As the Arlington community went live in March 2006, it was not included in the researcher's study.

136 Backfence.com, “Backfence Inc., Leading Hyperlocal Online Citizens’ Media Company, Receives Funding,” [Accessed online: 13 October 2005], http://www.backfence.com/about/index.cfm?page=/press/101205\&mycomm=BE. 
any mainstream media affiliation, lacking established ties to any newspaper, television network or other facet of "old media.” Because of its independence, backfence.com has received considerable academic attention from American Journalism Review and mainstream outlets, such as PBS' "News Hour with Jim Lehrer."

Bayosphere.com, the brainchild of participatory media scholar Dan Gillmor, is based in San Francisco. Gillmor, a former print reporter for The San Jose Mercury News, founded a non-profit called the Center for Citizen Media, and wrote We the Media: Grassroots Journalism For the People, By the People, which was perhaps the first work regarding hyperlocal media. His site is a cooperative of local bloggers in the Bay Area, a region notorious for its high-tech residents. Bayosphere’s local blogroll links to several Bay Area citizen journalism projects.

\section{Media Analysis Methodology}

The researcher's informal examination of the hyperlocal sites featured measurements, including frequency counts of various topical elements. (For detailed information regarding the study’s coding scheme, please see Appendix A).

\section{Archival Time Frame and Data Collection Procedures}

For the content examination, the researcher identified a random start date (Oct. 30, 2005) for backfence.com postings. The researcher also identified a random start date (Dec. 18, 2005) for bayosphere.com postings. For each website, the researcher employed a 5-day constructed week (Oct. 30, 2005 to Dec. 9, 2005 for backfence.com; Dec. 18, 2005 to Jan. 27, 2006 for bayosphere.com). Archiving the website's commonly-accessed portions over a multiple-week time span accounted for posts that might be quickly 
revised or removed, as well as topical issues that may rise or decline in prominence. At 8 p.m. on each archival date, the researcher saved each site's home page.

For backfence.com, the researcher saved articles featured on the home pages of all three communities: Bethesda, McLean and Reston. Only news stories and opinion linked to the site's main page were examined. The sections reviewed include the home page's highlights, news and voices sections. (The site’s Yellow Pages, classifieds, community guide and calendar were not the analysis' central focus, and therefore, were eliminated from the study).

The researcher considered entire discussion threads on both sites, including commentary. In this manner, the researcher could assess the level of interactivity. As previously stated, Rafaeli suggested that "interactivity requires a thread of messages; i.e., a chain of interrelated messages." ${ }^{137}$ Subsequent online messages must reference earlier postings to be considered truly interactive. ${ }^{138}$

For bayosphere.com, the researcher saved some citizen journalist sites linked in Gillmor's blogroll as well as the bayosphere.com homepage itself. Like backfence.com, the sites were informally examined for posting frequency and salient discussion threads.

It should be noted that the Internet is a public forum. Individuals writing on blogs or posting to hyperlocals are performing the act of publication. Both backfence.com and bayosphere.com are citizen journalism forums that are visible to all Internet users, as a password is not required to view postings. In short, the communities examined were deeply permeable to entry. Therefore, analyzing blogosphere content differs from

\footnotetext{
${ }^{137}$ Schultz, "Interactive Options in Online Journalism,” 1.

${ }^{138}$ Rafaeli, Interactivity, 111.
} 
examining listserv postings, for example, because those users have an expectation of privacy.

On the contrary, a scholarly examination of citizen journalism sites parallels a newspaper content analysis. Nevertheless, to ameliorate any privacy concerns regarding this research, the author did not use any poster or usernames when referencing specific grassroots media postings.

Interviewing Methodology

The researcher selected key informants from bayosphere.com and backfence.com for telephone interviews, which averaged one hour in length. The researcher initially sought face-to-face interviews and expressed interest in hands-on ethnographic participant observation at the hyperlocal sites profiled in this study. However, subjects expressed time constraints for any immersion work. Interview participants included:

- Mark Potts, Executive Vice President, backfence.com

- Dan Gillmor, founder, Center for Citizen Media and bayosphere.com

- Sean Bonner, founder, metroblogging.com

Barry Parr, a local Bay Area blogger, was also consulted. The researcher employed an interview schedule (which is summarized in Appendix B). The researcher sought interviews with female bloggers and citizen journalists associated with the two hyperlocal sites, but subjects declined to participate.

As mentioned previously, the exchanges were highly emergent and exploratory in design and often included follow-up questions. In general, each subject was questioned about his historical involvement with hyperlocal media, factors toward hyperlocal 
success or failure, demographics/characteristics of users and posters, specific content on the sites, policies on gatekeeping and the forecast for citizen journalism's future.

Telephone interviews exceeding 15 minutes were recorded and transcribed. In addition, the principal investigator took notes during the telephone exchanges. The analysis consisted of examining recurrent themes in the participant conversations.

\section{Institutional Review Board Approval}

In-depth interviews conducted by the principal investigator involved interaction with human subjects. Therefore, to protect participants in the research and minimize any harm to said subjects, the researcher sought approval from West Virginia University's Institutional Review Board before collecting data. This research is fully sanctioned by the School's governing IRB. (For more information about the IRB protocol, please see Appendix C. IRB approval documentation for this study is also included in the appendix). 


\section{EAST COAST CASE STUDY: WASHINGTON, D.C.}

"This is not kids typing 'Metallica rules." "

- Mark Potts, backfence.com ${ }^{139}$

\section{History}

Mark Potts began his journalism career in a sleepy Connecticut suburb where he delivered the news - as a paperboy. Years later, he distinctly recalls an element of his hometown gazette. Every day, the paper had several column inches dedicated to community news, a section Potts refers to as a "letter from the suburbs."

“It was the most mundane stuff in the world...the O’Reillys' have just got back from their vacation to the Bahamas, or so and so had a grandkid in Nevada. And it's really mundane stuff, but to the people who care about that stuff, it's the most important thing in the world. It's a small audience, but you add a lot of small communities together, and I think you have something."141

That something is backfence.com, a hyperlocal Internet community Potts co-

founded.

Potts, a former Washington Post reporter and editor, grew frustrated with the MSM model for the D.C. metro. He says traditional, printed publications are struggling to provide online local news. "I can go to Yahoo! News, Google News, washingtonpost.com, nytimes.com and find out what's going on with [Ariel] Sharon or in Iraq or in national politics,” Potts said. “I can’t find out what’s going on down the street." ${ }^{142}$

\footnotetext{
${ }^{139}$ Mark Potts, interview by author, transcript, telephone interview, 17 January 2006.

140 Ibid.

${ }^{141}$ Ibid.

142 Ibid.
} 
The vast size of The Washington Post's geographic community presents a manpower challenge, Potts says. As the bedroom communities adjoining the nation's capital blossomed, the Post's reporters and editors struggled to effectively cover the massive service territory. For instance, more than 1 million people live in Fairfax County. The Washington Post has only 12 reporters for the region, Potts says. "I don’t think there's another place in the country that has a million people and 12 reporters covering it,” he said. ${ }^{143}$

Consequently, professional journalists cannot possibly report on every council meeting and every high school sporting event. In contrast, Potts says he has hundreds of citizen journalists covering the territory for backfence.com's two Fairfax-based hyperlocals, located in Reston and McLean. ${ }^{144}$

In order to pursue his dream of neighborhood-based grassroots journalism, Potts departed his day job as a Post business reporter. (In addition to his editorial duties at the paper, Potts had co-founded the publication's Internet site, washingtonpost.com). ${ }^{145}$ Months after his departure from traditional news, Potts still describes himself as a “recovering journalist.”146

\footnotetext{
143 Ibid. 144 Ibid. 
Potts abandoned his newsroom desk to work with business partner Susan Defife from his kitchen table, which served as the website's nerve center for several months. ${ }^{147}$ In August 2004 with \$100,000 venture capital seed money, Potts and Defife formed backfence.com. $^{148}$

Potts’ portal aspires to be the modern-day equivalent of a zoned, neighborhood newspaper section. In that sense, Potts says he didn’t encounter problems in convincing the public about the site's value:

"You'd give people two sentences to describe it, and they'd go, 'Oh my God, I could use this to get a plumber.' We thought we'd have some people tell us, 'This is the craziest thing I've ever heard of.' And we haven't gotten that at all. The real sense is, 'Oh my God, can you bring this to my town?',"149

But bringing backfence.com to its initial trio of towns wasn’t exactly easy. In fact, the site's very technology daunted and frustrated its founders, Potts said. On the day of the site's beta launch, the team boldly scrapped its technology platform at the eleventh hour. The off-the-shelf software - one that Potts' team had purchased to start backfence.com - had performed as expected; no technical glitches were reported and few complaints were registered. Yet the site lacked ease-of-use and interactive functionality two key attributes Potts felt could influence the site's success or failure. ${ }^{150}$ Dan Gillmor, a citizen media advocate, fervently agrees user-friendly technology is vital to a

\footnotetext{
${ }^{147}$ News Hour with Jim Lehrer, “Extended Interview: Mark Potts and Susan Defife,” Public Broadcasting Corporation (May 2005).

148 PressThink, “Guest Writer Liz George of Baristanet Reviews Backfence.com Seven Months After Launch,” [Accessed 21 January 2006], http://journalism.nyu.edu/pubzone/weblogs/pressthink/2005/11/30/lz bcfc.html.

149 Mark Potts, interview by author, transcript, telephone interview, 17 January 2006.

${ }^{150}$ Ibid.
} 
hyperlocal's success. "You definitely need technology that makes things easy for people," he said. ${ }^{151}$

So every minute element of backfence.com was redesigned by hand. To the naked eye, the revamped site is rather plain and simple. Colored, hyperlinked tabs on the homepage introduce the site's areas reserved for news, community guide, voices, calendar, photos, Yellow Pages and classifieds. Even seemingly minor design flourishes serve a purpose, Potts says. "We wanted to go with very soft edges to the site rather than hard, sharp edges to give people the idea that, look, this is a friendly, family kind of place."152

After design modifications were complete, the first two community sites, Reston and McLean, went live on the World Wide Web. ${ }^{153}$ (Popular blog FishBowl DC notes Reston and McLean were also targets for The Washington Post's first community blog). ${ }^{154}$ Five months later, the citizens’ media company received a \$3 million infusion from New York venture capital group SAS Investors and from Omidyar Network, an investment fund chaired and financially supported by e-Bay founder Pierre Omidyar. ${ }^{155}$

${ }^{151}$ Dan Gillmor, interview by author, transcript, telephone interview, 26 January 2006.

152 Mark Potts, interview by author, transcript, telephone interview, 17 January 2006.

153 Backfence.com, “Backfence Inc., Leading Hyperlocal Online Citizens’ Media Company, Receives Funding," [Accessed online 13 October 2005], http://www.backfence.com/about/index.cfm?page=/press/101205\&mycomm=BE.

154 Fishbowl DC, “Hyperlocal Site Wins \$3M in Funding,” [Accessed online 19 Oct 2005], http://www.mediabistro.com/fishbowlDC/online_media/hyperlocal_site_wins_3m_in_funding_27067.asp.

155 Backfence.com, “Backfence Inc., Leading Hyperlocal Online Citizens’ Media Company, Receives Funding,” [Accessed online 13 October 2005], http://www.backfence.com/about/index.cfm?page=/press/101205\&mycomm=BE. 
The start-up site also formed an advisory board and hired six employees. In October 2005, the company unveiled its third hyperlocal community based in Bethesda. ${ }^{156}$

\section{Entering the community}

On each backfence.com homepage, dozens of hyperlinks encourage users to “Add a new topic!” Another homepage banner ad, featuring a middle-aged soccer mom, instructs fellow citizen journalists to "Let your neighbors know how your kid did in the big game." And a thought bubble at the bottom of the page reminds, "What do you think? Post It!”

In short, backfence.com is begging for content.

Even though repeated pleas for content submission abound on the site, users must provide personal information before sharing news stories. Prospective citizen journalists must register by providing a valid name, address, zip code and age. ${ }^{157}$ In addition, all members must be at least 13-years-old. ${ }^{158}$ Citizen journalists must also select a user name and password. Individuals can choose pseudonyms for backfence.com postings, but the site’s “Community Rules” kindly ask registered users to post information using real names, if possible. ${ }^{159}$

\footnotetext{
156 Ibid.

157 Backfence.com, “Community Agreement,” [Accessed online 6 March 2006], http://www.backfence.com/about/index.cfm?page=/membeers/commRules\&mycomm=RE. 158 Ibid.

159 Backfence.com, “Community Rules,” [Accessed online 6 March 2006], http://www.backfence.com/about/index.cfm?page=/membeers/commAgree\&mycomm=RE.
} 
BusinessWeek, in its lengthy feature on citizen media, suggested each of the three Washington-based hyperlocals attracts 6,000 to 7,000 readers. ${ }^{160}$ Backfence.com officials do not disclose its number of registered users. ${ }^{161}$ Potts describes that the site's success is viewed through a continuum from page views to registered users to site postings. ${ }^{162}$ As backfence.com establishes itself in the D.C. metro community, he hopes to first attract more readers, then more users, and finally, more posters. Potts would not divulge page view, registration or posting statistics. However, he affirmed the accuracy of an estimate posted on Jay Rosen's PressThink new media criticism blog, which suggested backfence.com had 600 users. ${ }^{163}$

“In relation to washingtonpost.com or nytimes.com, it’s not that big, but for a small community, it's a lot,” Potts said. ${ }^{164}$ Then again, the issues discussed on backfence.com are minor, niche topics that may only interest a couple hundred people, Potts says. ${ }^{165}$ And he also notes the number of registered users has increased since the PressThink blog posting was published in fall $2005 .{ }^{166}$

\footnotetext{
${ }^{160}$ Heather Green, “Online Extra: News You Can Use - and Write; Bayosphere's grand plans may be history, but many more community Web sites have taken its lessons to heart, letting everyday citizens deliver news,” BusinessWeek, 20 February 2006.

161 Mark Potts, interview by author, transcript, telephone interview, 17 January 2006.

162 Ibid.

163 PressThink, “Guest Writer Liz George of Baristanet Reviews Backfence.com Seven Months After Launch.”

${ }^{164}$ Mark Potts, interview by author, transcript, telephone interview, 17 January 2006.

165 Ibid.

${ }^{166}$ Ibid.
} 
Even though registration may limit Backfence's usage statistics, Potts believes requiring information from posters may prevent some individuals from making disparaging remarks on the site’s boards. "I think it prevents people from taking a shot at someone and then disappearing," Potts said. ${ }^{167}$ Even though virtual community entry is not deeply permeable, intricate programming knowledge is not required for posting content. Thanks to open source software, users simply enter writings into text boxes resembling blank, ready-to-compose e-mail messages. Then, visitors click on the word "publish," which automatically posts remarks to the site. After submission, users cannot edit or delete backfence.com postings. ${ }^{168}$

Although backfence.com truly functions as a group blog, its editors carefully avoid such net jargon - a conscious choice according to Potts.

"Blog is such a loaded word," Potts said. "Either people don't know what it is or they think they know what it is. And so we wanted all the functionality of a blog or wiki without any of the jargon. You type an e-mail to a friend is what you think you're doing on this thing. You're filling out a form, and you hit publish, and it's up there. If you know blogging, does it look like a blog? You bet your life it does." ${ }^{\prime 69}$

Nevertheless, backfence.com differs from the traditional blogosphere in one respect. Backfence.com employs a content manager, who regularly examines the site to gauge community debate. The content manager decides which stories will be spotlighted on the site's homepages. Twice daily, the editor chooses the most active or entertaining

167 Ibid.

168 Backfence.com, “Community Rules,” [Accessed 21 January 2006], http://www.backfence.com/about/index.cfm?page=/membeers/commAgree\&mycomm=RE.

169 Mark Potts, interview by author, transcript, telephone interview, 17 January 2006. 
posts to be featured. ${ }^{170}$ Potts emphatically says most posts are not censored; writings are only removed if the content is deemed offensive or inappropriate. The content manager merely facilitates the online dialogue, Potts says.

\section{Creating news content}

In the site’s recesses, novice journalists can find a how-to guide on writing effective news stories. According to the tutorial, backfence.com users must focus solely on local news, and must write using extensive detail. ${ }^{171}$ Although the site's editors say they prefer original journalism, backfence.com accepts press releases, which generates a high number of hyperlocal posts.

In addition, the site's editors urge its users to be truthful and concise in their reports. ${ }^{172}$ Ironically though, those behind the site also remind members to "Take what you find on backfence.com with a grain of salt. There is no substitute for a healthy skepticism and your own good judgment."173

Judgments abound on the site's voices section, which serves as the hyperlocal's op-ed page. And in addition to written content, individuals are also invited to submit photos. Around the holiday season, users were asked to capture images of neighborhood lights and decorations. The online, hometown competition for Clark Griswold-like festive supremacy quickly ensued.

\footnotetext{
170 Ibid.

${ }^{171}$ Backfence.com, “Community Rules,” [Accessed 21 January 2006], http://www.backfence.com/about/index.cfm?page=/membeers/commAgree\&mycomm=RE.

172 Ibid.

${ }^{173}$ Ibid.
} 
Haute cuisine, hot rod repair shops and hour photo locations are reviewed with honest intricacy on the site's Community Guide, which allows readers to share experiences with local, small businesses. Backfence.com's Yellow Pages area provides maps, directions and phone numbers for all reviewed establishments. Potts calls the Yellow Pages' success “the biggest surprise of all” in the hyperlocal's launch. ${ }^{174}$ Many first-time visitors to backfence.com are referred through Google searches for local businesses, Potts says. ${ }^{175}$ In fact, the most popular site search term links to a Yellow Pages directory listing for a Tyson’s Corner restaurant. ${ }^{176}$

"It's not the primary business, but it's the currency of information that's passed around by neighbors in a town... and we thought this is as important as news, making that available,” Potts says. ${ }^{177}$ He hopes the unique combination of features will make backfence.com a marketable hyperlocal site. "I'm not aware of any site, any hyperlocal, that's got blogs, wikis, Yellow Pages, classifieds and photo galleries like we do. We just wanted to put it all up there so that people can use it if they wanted to use it.”178

During an informal five-week study window, the researcher examined how backfence.com members used the citizen media site. In total, the homepages of all three backfence.com communities featured 85 news and opinion postings.

\footnotetext{
${ }^{174}$ Mark Potts, interview by author, transcript, telephone interview, 17 January 2006.

175 Ibid.

${ }^{176}$ Ibid.

177 Ibid.

178 Ibid.
} 
The site fosters “thoughtful discourse," Potts says. ${ }^{179}$ Users are asked to "Put in your two cents. You can say as much or as little as you'd like.”180 Potts believes backfence.com users are saying quite a lot. “They’re not writing one sentence replies; they’re writing multiple paragraphs,” he said. “This is not kids typing 'Metallica rules.

\section{Bethesda, Md.}

The Bethesda Backfence was unveiled in October 2005, making the site the youngest D.C.-based hyperlocal. The site’s founders define the perimeter for each backfence.com virtual community along geographic lines, using a combination of zip codes and local schools as landmarks.

U.S. Census figures estimate 55,277 residents live in Bethesda, a region that has been shrinking in size since $1970 .{ }^{182}$ More than 85 percent of its residents are Caucasian, and the median household income exceeds $\$ 130,000 .{ }^{183}$ In addition, Bethesda boasts the best-educated population of any American city exceeding 50,000 people, as nearly 80 percent of its residents possess college diplomas and nearly half completed graduate or

179 Ibid.

180 Backfence.com, “Backfence,” [Accessed 21 January 2006], http://www.backfence.com/about/index.cfm?page=/membeers/commAgree\&mycomm=RE.

181 Mark Potts, interview by author, transcript, telephone interview, 17 January 2006.

182 Ibid.; Backfence.com, “How We Define Your Backfence Community - Reston,” [Accessed 21 January 2006], http://www.backfence.com/about/index.cfm?page=/membeers/howDefine\&mycomm=RE.; Wikipedia.org, "Bethesda,” [Accessed 21 January 2006], http://en.wikipedia.org/wiki/Bethesda\%2C_Maryland.

183 Wikipedia.org, “Bethesda,” [Accessed 21 January 2006], http://en.wikipedia.org/wiki/Bethesda\%2C_Maryland. 
professional degrees. ${ }^{184}$ Prominent government agencies in Bethesda include the National Institutes of Health and the Bethesda Naval Hospital. ${ }^{185}$ Lockheed Martin and Marriott also have corporate headquarters in the area. ${ }^{186}$

Over the five-week study period, the Bethesda homepage featured 36 unique postings. Therefore, Bethesda - the newest of the three backfence.com hyperlocals displayed the highest activity level. Some discussions may appear banal to the distanced online observer. For instance, one writer asked for feedback in finding the perfect snow shovel before impending inclement weather. Another citizen journalist posted to praise the inclusion of costumed clowns in the town's library anniversary celebration. (And just in case there was any doubt as to the presence of the aforementioned circus performers, the amateur reporter added a photo of a clown crafting a balloon animal). ${ }^{187}$

Bethesda's gridlocked streets, suffocating congestion and towering development fuel a stressful, suburban three-ring circus, posters frequently gripe. One such substantive discussion thread on the Bethesda boards encompassed recent zoning ordinances. In one post, a citizen journalist questioned recent construction at the Sycamore Store, a vacant building that once housed an all-purpose general store. ${ }^{188}$ The establishment, which had been closed for years, now had a construction permit hanging in the window. The

\footnotetext{
184 Ibid.

185 Ibid.

186 Ibid.

${ }^{187}$ Backfence.com, “Gearing up for the Second Storm of the Week;” Backfence.com, "Bethesda Library Anniversary Celebration Clowns Around." It should be noted that for backfence.com postings, the URLs are slightly dynamic - therefore, the links are not listed in the study's footnotes.

188 Backfence.com, “Sycamore Store?”
} 
backfence.com poster asked the community for feedback. Some of the questions posted included: Does anyone know who owns the store? Will they reopen the shop?

Within a few days, the new Sycamore property owner replied, stating his intentions for the Montgomery County landmark. The proprietor, who plans on remodeling the structure to serve as an office for his architectural firm, expressed his long-time residency and his concerns for the community's future development. That's why he purchased the property. He even established a website where community members could learn about his respect for keeping the historical edifice intact.

In another post, Bethesda residents expressed dismay at dwindling shopping opportunities at Woodmont Corner, a pedestrian retail district in downtown Bethesda. ${ }^{189}$ Several restaurants and stores had closed for business recently, posters noted. One writer lamented over her emotional quest to find the perfect hamburger after the closure of a popular Woodmont pub. Many replies referenced the shopping center’s history, reminiscing to the days when Woodmont boasted an arcade and carousel.

As evidenced, nearly every post on the Bethesda hyperlocal referenced strong, long-term ties to the Washington, D.C. suburb. Potts affirms that most posters are not mere transients. "The people we have [on backfence.com] are long-time residents, if not lifetime residents of the communities we're in,” Potts said. 190 "They have a really deepseated love of the community.”

Yet not all posts were marked by sunny nostalgia. In one case, a patron complained on the hyperlocal about the service he received regarding handicapped

\footnotetext{
189 Backfence.com, “Flanagan’s Gone! Woodmont Corner Dissolving.”

190 Mark Potts, interview by author, transcript, telephone interview, 17 January 2006.
} 
accessibility at a local entertainment venue. ${ }^{191}$ After listing his litany of complaints with elevator and ramp access, he asked for community feedback. Had anyone else encountered such experiences?

Several hours later, an official from the music hall in question defended the venue and its customer service record. In addition, several community members contradicted the original post, rather, concurring with more favorable reviews of the venue's handicapped accessibility. The original author, who had once griped about his arduous journey to reach his orchestra box seats, posted again to thank the Backfence community for its feedback.

Similarly, several posts included replies from official sources connected to backfence.com citizen journalist stories. Concurrently, local politicos have been early adopters of the hyperlocal community, too. Many elected officials routinely post "good news" press releases about district work. For example, some posts referenced office hour availability for state General Assembly members. ${ }^{192}$

Backfence.com is not the only citizen journalism community that has contended with politicians fostering positive public relations by posing as citizen journalists. A Denver-based hyperlocal, yourhub.com, has encountered politicians who routinely post “news stories."193

In the wake of expensive political electioneering, placing such "news" in hyperlocal media raises the debate as to whether the pieces are, in effect, campaign

191 Backfence.com, “Strathmore Music Hall - Disabled Patrons Beware.”

192 Backfence.com, “Del. Jean Cryor (R) Gives Pre-Session Talk.”

193 New West Politics, “Denver Media Offering Politicos Free PR Outlet,” [Accessed online 25 March 2006], http://www.newwest.net/index.php/topic/article/6537/C37/L37. 
advertisements. Unlike traditional political advertising, placing “stories” on sites like backfence.com and yourhub.com is completely free to candidates. One could argue that placing "news items” on a hyperlocal has a greater "degree of implied authenticity that elevates them beyond anything a paid ad could dream to achieve,” as one writer suggests. $^{194}$

Political posts were also present on the McLean hyperlocal, which we will examine next.

\section{McLean, Va.}

Founded in 1910 by the merger of two communities, McLean's namesake is a former Washington Post editor. ${ }^{195}$ McLean is an unincorporated community in Fairfax County, Virginia. ${ }^{196}$ As previously mentioned, zip codes and local schools define the McLean Backfence’s service territory. ${ }^{197}$

Home to nearly 70,000 residents, the McLean Backfence encompasses a slightly larger geographic community than the Bethesda or Reston hyperlocals. The region’s population swelled in the 1980s, nearly doubling its number of residents in one decade. ${ }^{198}$ Again, U.S. Census statistics suggest the community is not ethnically diverse; for nearly

194 Ibid.

195 Wikipedia.org, “McLean,” [Accessed 21 January 2006], http://en.wikipedia.org/wiki/McLean\%2C_Virginia.

196 Ibid.

197 Backfence.com, “How We Define Your Backfence Community - McLean,” [Accessed online 21 January 2006]: http://www.backfence.com/about/index.cfm?page=/membeers/howDefine\&mycomm=MC.

198 Wikipedia.org, “McLean,” [Accessed 21 January 2006], http://en.wikipedia.org/wiki/McLean\%2C_Virginia. 
eight in 10 of its residents are Caucasian. ${ }^{199}$ Median household income is estimated at nearly $\$ 138,000 .^{200}$ The region is home to the Central Intelligence Agency and USA Today. $^{201}$

Twenty-seven posts appeared during the study’s five-week observation window. Analogous to the Bethesda site, some posts would not merit the label of MSM "news." And like Bethesda, residents expressed deep concerns over commercial development. McLean residents often pay six-figure sums for modest homes. After the sale, most new homeowners in the Washington, D.C. suburb begin making massive renovations - drastic overhauls that often end in wholesale demolition of the structure itself. Known colloquially as “teardowns,” the homes are bulldozed and razed to make way for larger, more ostentatious estates. Backfence.com posters frequently take photographs of such recently sold real estate, noting the home’s appraised and listed prices. The pejorative discussion threads typically express bitter outrage toward the new property owners.

The Reston and McLean sites feature weekly crime reports, which synopsize public police blotters, which reveal a wide spectrum of criminal offenses. Property values and police reports are public documents, which must be procured from various governmental agencies. In this light, citizen reporters are approaching traditional journalism, which is a largely document-centric craft.

\footnotetext{
199 Ibid.

200 Ibid.

201 Ibid.
} 
By far, the most contentious post contained an argument that was ultimately adjudicated by the Virginia Supreme Court. ${ }^{202}$ The debate centered on whether a local, community soccer field should be shared between community organizations and colleges. The state's highest court, in a 7-0 opinion, ruled against sharing the sports facilities.

The Backfence posting expanded greatly upon MSM reports from The Washington Post. Citizen journalist posts linked to the disputed zoning ordinances and legal petitions. In addition, residents with property bordering the soccer field expressed personal concerns regarding traffic flow and noise levels if the field would be shared among multiple parties. The rancorous discourse even resulted in one poster apologizing to another.

The backfence.com debate commenced on June 5, 2005. And even though the legal case had been settled, the online discussion continued back and forth as of this writing. Potts said he wasn't surprised at the rancor and outrage surrounding the Lewisville soccer field case. In fact, he anticipated that youth sports would be the central focus for McLean citizen journalists.

"McLean is a sports-crazy town," Potts said. "Every kid in town plays, like, four or five sports. ${ }^{203}$ In fact, Potts worries that athletic discussion dominates conversation on the McLean hyperlocal. ${ }^{204}$ Yet avoiding sports-centric talk is difficult, if not impossible, as the town's Little League team routinely competes in the upper echelons of the National Championship. It's part of the blood and marrow of the community, many say.

\footnotetext{
202 Backfence.com, "The Great Lewinsville Soccer Controversy.”

${ }^{203}$ Mark Potts, interview by author, transcript, telephone interview, 17 January 2006. 204 Ibid.
} 
In fact, one of McLean's most active posters coaches high school soccer and track teams. He routinely writes about how his teams fare, even if the athletes didn't have a blue ribbon finish, Potts notes:

"He recently wrote a post about his team finishing third. Most reporters don't write about third place teams. You write about the winners. But people who are at school, people who are parents of those kids, it's important to find out how that team did and who scored what. I mean, third place is fantastic in a meet of 15 schools. So it's that kind of feeling, reporters don't write about a third place team because that's not what's important. But for people who are interested in that, who cares about the first place team?"205

In another sports-related posting, community leaders appealed for reader support

for a local child afflicted with a rare form of leukemia. ${ }^{206}$ One poster, who organized a 5k run to benefit the child, invited users to share stories about the family. Following the poster's lead, many contributed their thoughts, well wishes and prayers to the Backfence site. Sadly, in late 2005, the child lost his battle.

During the period of study, the popularity of employing community organization press releases was more prominent on the McLean site than the other Backfence hyperlocals. Testimonials for lesser-known political candidates also appeared on the hyperlocal. As in Bethesda, the political postings raise interesting questions about the future of hyperlocal campaign advertising and whether such online advocacy should be regulated like traditional media campaign advertising.

\footnotetext{
${ }^{205}$ Mark Potts, interview by author, transcript, telephone interview, 17 January 2006.

${ }^{206}$ Backfence.com, “5k Race to Raise Funds for Cameron McClain.”
} 


\section{Reston, Va.}

The Reston hyperlocal encompasses nearly 55,805 metropolitan residents

stretched over three zip codes, says backfence.com. ${ }^{207}$ Like the previous two hyperlocals, the Reston site also includes a list of public schools that are considered within the hyperlocal's coverage area. ${ }^{208}$ However, recent U.S. Census data suggests the population is slightly larger than the backfence.com estimate. ${ }^{209}$ And similar to McLean and Bethesda, the community lacks ethnic diversity as nearly 80 percent of Reston's residents are Caucasian. The region’s primary employers include Sprint and Sallie Mae. ${ }^{210}$ The median income for residents is nearly $\$ 95,000 .^{211}$

Founded in 1964, Reston is an unincorporated planned community in Fairfax County, Virginia. ${ }^{212}$ Developer Robert E. Simon envisioned the combination of green space with a mixed-use industrial and residential district, spanning over 6,750 acres. ${ }^{213}$

(The community’s name stems from Simon's initials). ${ }^{214}$ By 1970, Reston only had 5,700

\footnotetext{
207 Backfence.com, “How We Define Your Backfence Community - Reston,” [Accessed 21 January 2006], http://www.backfence.com/about/index.cfm?page=/membeers/howDefine\&mycomm=RE. 
residents. ${ }^{215}$ However, as the Washington, D.C. metropolitan expanded, the bedroom community blossomed in the 1980s. ${ }^{216}$

Despite a booming population, the planned development unveiled in the mid1960s continues. Today, a “Design Review Board” controls zoning so carefully that homeowners must seek approval for every facet of home remodeling, including outdoor paint colors. ${ }^{217}$ Therefore, postings critical of suburban zoning and development were less prevalent on the Reston hyperlocal than the Bethesda and McLean sites.

The research study captured 21 homepage posts during the content analysis period, making Reston the smallest of the three backfence hyperlocals. Reston had a significant number of press releases on its hyperlocal compared to the other Backfence sites.

Not surprisingly, the hyperlocal's most heated discussion thread concerned whether Reston should incorporate as a town. ${ }^{218}$ The debate over Reston's unincorporated status has persisted for years, long before the advent of backfence.com. In 1980, an initiative to incorporate the suburb failed by a 2-to-1 margin. As Reston remains unincorporated, a grassroots movement called the Reston Citizens Association resurfaced in mid-2005 to advocate town status conversion.

The Citizens Association moderated the majority of dialogue on Reston’s Backfence. As the discourse contained a staggering 43 replies to the original post as of

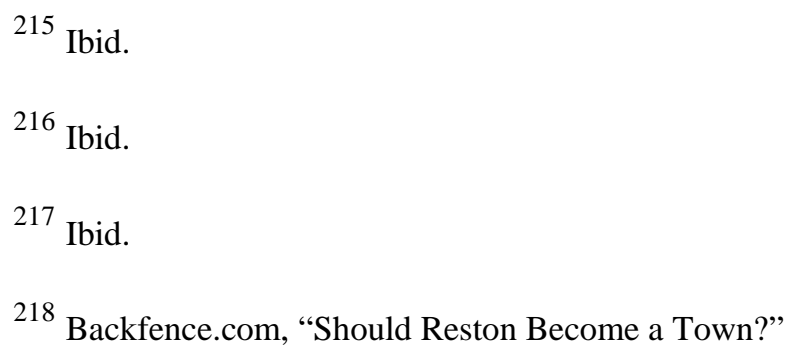


this writing, the town debate is the most active thread of all backfence.com communities. Potts purports reading the entire thread would probably take nearly an hour. ${ }^{219}$ Consequently, a link to the Reston town argument has remained a fixture of the hyperlocal homepage for several months, even though The Washington Post hasn’t touched the issue for years. "It's one of those evergreens that someone was saying, 'Gee, the topic’s been up there for a year. What's it still doing up there?’” Potts said. “And when we go to update the homepage, people start replying to it. It's just one of those great issues.”

${ }^{219}$ Mark Potts, interview by author, transcript, telephone interview, 17 January 2006. 


\section{WEST COAST CASE STUDY: SAN FRANCISCO}

“...this will be a long process of figuring out how this works."

- Dan Gillmor 220

\section{$\underline{\text { History }}$}

Thousands of miles apart, citizen media advocate Dan Gillmor shared a similar conundrum with backfence.com founder Mark Potts. Both men had established, esteemed MSM reporting careers, but felt drawn to the emerging world of open source news. In the end, Gillmor and Potts resolved their respective conflicts in the same manner - by quitting their day jobs. Gillmor, once a San Jose Mercury News columnist, departed his modest newsroom cubicle to pursue citizen journalism work full time. He says leaving the publication was "the right thing to do.",221

Consequently, he penned a book on citizen journalism, titled We the Media: Grassroots Journalism for the People, by the People.

Then, he ventured further into the blogosphere himself.

In February 2005, Gillmor teamed with Michael Goff, founder of Out Magazine, for a citizen media venture called Grassroots Media, a collaborative that would later launch bayosphere.com. ${ }^{222}$ Gillmor received financial backing from Omidyar Network, a venture capital investment firm who also lent financial support to backfence.com, among

\footnotetext{
220 Dan Gillmor, interview by author, transcript, telephone interview, 26 January 2006.

${ }^{221}$ Ibid.

222 Heather Green, “Great Online Expectations; Bayosphere wanted to reinvent journalism. Here's how the dream died,” BusinessWeek, 20 February 2006, 68.
} 
other user-driven, high-tech startups. ${ }^{223}$ The hyperlocal's motto urged the user-driven content would be “of, by and for the Bay Area."224

Among Silicon Valley’s digerati, Gillmor’s blog musings were worshipped enormously. Therefore, he hoped to lend his voice to the citizen journalism cause celebre, using his blog as the launching pad for a California-based grassroots reporting movement. After Gillmor secured funding, he took the site live in mid-2005. ${ }^{225}$

While the site's founders lauded that bayosphere.com would evolve into an alternative news outlet for the Bay Area, many connected to the site conceded the hyperlocal would likely become yet another online bastion for high-tech talk. Some critics of Gillmor's site, including Online Journalism Review writer Tom Grubisich, deeply questioned the percentage of posts dedicated to the tech community. ${ }^{226}$ In fact, one of the longest posts during the researcher's study window revolved around Apple Computer's annual consumer electronics show, MacWorld. ${ }^{227}$

Each bayosphere.com page contains a link to Gillmor’s personal blog. On his weblog, Gillmor occasionally touched on political controversies, and frequently mentioned his speaking engagement schedule. Nevertheless, Gillmor called Bayosphere,

\footnotetext{
223 Tom Grubisich, “What are the lessons from Dan Gillmor's Bayosphere?” USC Annenburg Online Journalism Review [Accessed 29 January 2006], http://www.ojr.org/ojr/stories/060129grubisich/.

224 Ibid.

${ }^{225}$ Dan Gillmor, interview by author, transcript, telephone interview, 26 January 2006.

${ }^{226}$ Ibid.

${ }^{227}$ Bayosphere.com, "MacWorld 2006: The Most Boring Macworld Ever!”
} 
his first official trial hosting a citizen journalism community, "an experiment as part of a testbed.”228 We will now examine Gillmor’s embryonic experiment in-depth.

\section{Entering the community}

Want to be a citizen journalist? Live in San Francisco?

Then, Dan Gillmor wanted you.

Each site visitor is welcomed into the hyperlocal fray, and is greeted by a link inviting their entry into the reporting realm. By clicking on the "Write now" button, users are redirected to a registration page.

Gillmor's pitch to would-be writers may strike a chord for the disaffected seeking an alternative outlet for news and information. "Are you dissatisfied with the way the news is reported in the major media?” Gillmor writes. "Do you want to amplify what you are reading and hearing in the press? Want to tell your neighbors what's happening? Did you see something newsworthy?”229 In return for registering as a citizen journalist, users can create and access personal blogs on the site. ${ }^{230}$

Yet for unrestricted entrée into Bayosphere’s inner sanctum, users must ‘sign’ a pledge, one that The Guardian described as "a statement of dedication to fairness, thoroughness, accuracy and openness.”231 The creed requires users disclose any conflicts

\footnotetext{
${ }^{228}$ Dan Gillmor, interview by author, transcript, telephone interview, 26 January 2006.

229 Bayosphere.com, “Be a Citizen Journalist,” [Accessed online 6 March 2006], http://bayosphere.com/be_a_journalist.

230 Ibid.

231 Bobbie Johnson, “Online blog watch: Citizen Chain,” The Guardian (U.K.), 30 June 2005, 20.
} 
of interest connected to their stories. ${ }^{232}$ (Gillmor affirms he will suggest that other startup hyperlocal practitioners present an informal ethics contract to perspective journalists. He believes the contract is a best practice for hyperlocal media). ${ }^{233}$

Gillmor's site also requires that registered citizen journalists use their real names for site postings. ${ }^{234}$ Employing real names rather than pseudonyms are essential for citizen journalist accountability, he says. "As a citizen journalist, you own your words and have responsibility for them,” the site notes. ${ }^{235}$ Would-be writers must also provide a valid address and telephone number - information that will remain confidential, the site's founders note. ${ }^{236}$ While limiting free and unfettered access appears antithetical to the citizen journalist mission statement, Gillmor says registration increases posting quality. ${ }^{237}$ “There appears to be a correlation between willingness to stand behind one's own words and the overall quality of what's said,” Gillmor wrote. ${ }^{238}$

\footnotetext{
232 Bayosphere.com, “Bayosphere Journalist Sign-up,” [Accessed online 6 March 2006], http://bayosphere.com/cjregister.

233 Bayosphere.com, "From Dan: A Letter to the Bayosphere Coummunity,” [Accessed online 24 January 2006], http://bayosphere.com/blog/dan_gillmor/20051228/bayospheres future.

234 Bayosphere.com, “Bayosphere Journalist Sign-up,” [Accessed online 6 March 2006], http://bayosphere.com/cjregister.

235 Bayosphere.com, “Why Real Names for Citizen Journalists?” [Accessed online 6 March 2006], http://bayosphere.com/real_names.

236 Ibid.

${ }^{237}$ Bayosphere.com, "From Dan: A Letter to the Bayosphere Coummunity” [Accessed 24 January 2006], http://bayosphere.com/blog/dan_ gillmor/20051228/bayospheres future.

${ }^{238}$ Ibid.
} 


\section{Bayosphere's Trials}

Despite rhetoric extolling the rise of open source news, the results of bayosphere.com’s ‘experiment’ surprised many - including Gillmor himself.

For nearly seven months, the new media pioneer toiled on the site. ${ }^{239}$ While Gillmor’s commentary established itself as a permanent fixture, outsider contributions were extremely limited. During the first three archival weeks in this research study, only one unique post written by a citizen journalist appeared on the site's homepage. The sole writer took a satirical glance at the supposed "War on Christmas,” an idea proffered by the conservative punditocracy that selected Americans and American corporations were not properly observing the Christian holiday. ${ }^{240}$

While some site discussion forums were active, writers were not submitting substantive news articles. In this sense, one could question whether Gillmor's ambitious start-up truly embodied an interactive medium. Again, Rafaeli suggested that “interactivity requires a thread of messages; i.e., a chain of interrelated messages." ${ }^{241}$ Not only did Bayosphere’s content lack a back-and-forth dialogue between members, but only a handful of posts ever appeared on the web itself. (An examination of the possible rationales behind the site's lack of interactivity will be explored later).

Although bayosphere.com had received considerable attention from professional journalists and academics, Gillmor’s vision was clearly not materializing online. "Many

${ }^{239}$ Grubisich, "What are the lessons from Dan Gillmor's Bayosphere?"

240 Bayosphere.com, "Merry Central East Oakland Christmas.”

${ }^{241}$ Schultz, “Interactive Options in Online Journalism,” 1. 
fewer citizens participated, they were less interested in collaborating with one another, and the response to our initiatives was underwhelming," Gillmor wrote. ${ }^{242}$

So in September 2005, Gillmor ceased drawing from his investor’s finances. ${ }^{243}$ Instead, he chose to operate the site on a bare-bones, cash-strapped budget. Shortly before the holiday season, Gillmor alluded to his struggle in taking bayosphere.com to critical mass. With a terse paragraph post added on December 28, 2005, Gillmor foreshadowed that the site may change ownership. In the message, he affirmed his support for bayosphere.com, though Gillmor's presence on the hyperlocal would likely be reduced as he focused on launching a non-profit. He explained that his work with the Center for Citizen Media, a non-profit think tank dedicated to studying grassroots journalism, would likely dominate his efforts in the new year. ${ }^{244}$

Less than one month later, Gillmor announced his informal departure from the site.

On January 24, 2006, he posted his musings as an extended letter to the site’s community. He says his first foray into citizen journalism “didn’t turn out” quite the way he had hoped:

I share the disappointment of some of our citizen journalists. And I respect their skepticism; we encouraged it, after all. It's definitely no fun to have disappointed folks (starting with Michael and our investors, and myself). Still, I owe those of you

\footnotetext{
242 Bayosphere.com, "From Dan: A Letter to the Bayosphere Coummunity” [Accessed 24 January 2006], http://bayosphere.com/blog/dan_gillmor/20051228/bayospheres future.

243 Ibid.

244 Bayosphere.com, “Bayosphere’s Future” [Accessed online 3 January 2006], http://bayosphere.com/blog/dan_gillmor/20051228/bayospheres_future.
} 
who participated and visited my thanks for being part of the experiment. ${ }^{245}$

In his letter, forthright in its transparency and honesty, Gillmor placed responsibility for the site's tepid interactivity squarely upon his own shoulders. "But as is obvious to anyone who's paid attention, the site didn't take off - in large part, no question about it, because of my own miscues and shortcomings," Gillmor wrote. "My friend Esther Dyson says, wisely, 'Always make new mistakes.’ Did I ever.”246

In an interview with the researcher, Gillmor would not expand upon the mistakes outlined in his missive to the bayosphere.com faithful. (Gillmor's self-admitted missteps will be explored in detail later in this research). ${ }^{247}$ He pointed to the site's unknown future as to his hesitancy to expand upon his online remarks. Gillmor did note, however, he was thankful the community had received his confessional with open arms. "I think people have raised a lot of good points and I've been gratified about the understanding that people have and in particular, that the understanding that this will be a long process of figuring out how this works...,248

Some media reports have claimed the site's lack of oversight may have ushered its ultimate downfall. ${ }^{249}$ Gillmor acknowledges that a strong, hyperlocal community must closely monitor site content for the medium to work. ${ }^{250}$ "What's necessary for any

\footnotetext{
${ }^{245}$ Bayosphere.com, "From Dan: A Letter to the Bayosphere Coummunity.”

246 Ibid.

${ }^{247}$ Dan Gillmor, interview by author, transcript, telephone interview, 26 January 2006.

248 Ibid.

249 Green, “Great Online Expectations,” 68.

${ }^{250}$ Dan Gillmor, interview by author, transcript, telephone interview, 26 January 2006.
} 
participatory project is a sense of ownership," Mini Kahlon, a Bayosphere participant, told BusinessWeek. "That was missing."251

Two months after the researcher's interview with Gillmor, many bayosphere.com homepage links appeared to be dead. The site's title bar, which had an FAQ tab, led the reader to a simple message: “Page not found.” With Gillmor’s departure, the site’s future is extremely clouded, as the hyperlocal lacks investment backing or institutional support.

In his new, non-profit role at the Center for Citizen Media, Gillmor plans to consult and train hyperlocal editors to build better virtual communities, he says. ${ }^{252} \mathrm{He}$ also hopes to conduct think tank research on grassroots journalism. For his advocacy work, he has already allied academic partnerships with the Harvard Berkman Center for Internet and Society and the U.C. Berkeley Graduate School of Journalism. ${ }^{253}$

Despite his trials with Bayosphere, Gillmor's viewpoint on citizen media remains highly esteemed by hyperlocal practitioners. "He's the reason we're all here," Susan DeFife, co-founder of backfence.com, told BusinessWeek. "He has an incredible vision about what this should be."254

\footnotetext{
251 Green, “Great Online Expectations,” 68.

252 Dan Gillmor, interview by author, transcript, telephone interview, 26 January 2006.

253 Ibid.

254 Green, “Great Online Expectations,” 68.
} 


\section{$\underline{\text { Metroblogging.com }}$}

Remaining Bay Area hyperlocal practitioners are attempting to fulfill Gillmor’s “incredible vision.” Perhaps the most ambitious California-based project boasts a network of 40 hyperlocal sites, titled under the umbrella, Metroblogging.

Brainstormed over a simple cup of coffee, the network presents an ambitious step in the world of citizen media, says co-founder Sean Bonner. ${ }^{255}$ After conferring with his business partner, Jason DeFillippo, Bonner combed the local California-based blogosphere for possible site contributors. ${ }^{256}$ "We just wanted to kind of get a feel for things we should be paying attention to in the city,” Bonner said. ${ }^{257}$ After the informal blogger scan, Bonner e-mailed possible citizen journalists and explained his vision, asking for their participation. ${ }^{258}$ The network’s first site - based in Los Angeles launched nearly two years ago, he notes:

"We [Bonner and DeFillippo] both had the idea that we should get a bunch of these people and put together a site and have them all sort of pull those tips about anything about life in Los Angeles, you know, into one place so that anyone else who was looking for kind of bloggers talking about the city itself. They'd have one place to go and a whole bunch of different voices chiming in on it. And you'd get a pretty good idea of just what's going on.”259

\footnotetext{
${ }^{255}$ Sean Bonner, interview by author, transcript, telephone interview, 20 January 2006.

256 Ibid.

${ }^{257}$ Ibid.

258 Ibid.

${ }^{259}$ Ibid.
} 
Soon after unveiling the Los Angeles site, Bonner says he received queries from bloggers across the country asking for similar hyperlocal sites in their cities. ${ }^{260}$ (The advocacy to extend the Metroblogging network closely parallels Potts' description of those appealing for additional backfence.com hyperlocals). In two years, Bonner expanded his network to encompass 40 hyperlocal sites spread throughout the world. ${ }^{261}$

To add another city to the network, Bonner initially tries to identify 10-20 local bloggers who will commit to regularly writing on the site. ${ }^{262}$ Each blogger is informally expected to post two or three writings weekly, Bonner suggests. ${ }^{263}$ With a volunteer-only support network, e-mail missives containing story ideas are normally exchanged among writers. Bonner sometimes submits story tips to his local bloggers to varied success:

"Usually, if something is happening, on a local level enough that it’s being covered nationally, our people are already on it. They're aware that it's a big story, and they're on it before I know about it. But certainly, if I see something that is interesting or something I'm curious about or whatever and I don't see it on the blog, then I'll certainly send it to the mailing list of that city and say, hey, do you know anything about this or whatever.,264

Despite interactivity among the site's primary authors, the hyperlocal itself has limited interactivity for its casual users. Unlike other citizen journalism sites, visitors can only leave comments on Metroblogging; they cannot post entire stories unless they are one of the approved bloggers.

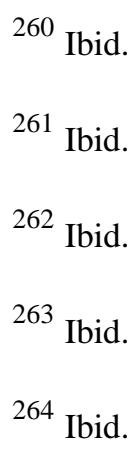


Metroblogging's network costs are funded through advertising, although the site does not generate much additional revenue, Bonner says. ${ }^{265}$ Any profits are divided equally between hyperlocal contributors, he adds. ${ }^{266}$ Like Backfence and Bayosphere, Bonner would not unveil the number of visitors that his site generates. ${ }^{267}$

Like bayosphere.com, Bonner’s San Francisco outlet is dominated by high-tech news, its founder says. ${ }^{268} \mathrm{He}$ adds the Bay Area blog is set apart from the 39 other hyperlocals on his network because of its "focused readership.",269

Some Metroblogging stories resemble traditional news reports. One writer’s statistical examination of public transportation fare hikes, for instance, contained numerous quotes from official sources, and was written in inverted pyramid format - a style favored by professional journalists. ${ }^{270}$

Despite some professional posts, the site's overall tone loosely mirrors an altweekly paper. Some of the hyperlocal's stories are humorous, as in the case of one Metroblogging contributor who watched a falling tree smash a Honda CRV. ${ }^{271}$ (Apparently, her post proves that if a tree falls near a blogger, it does indeed make a sound - at least in the blogosphere).

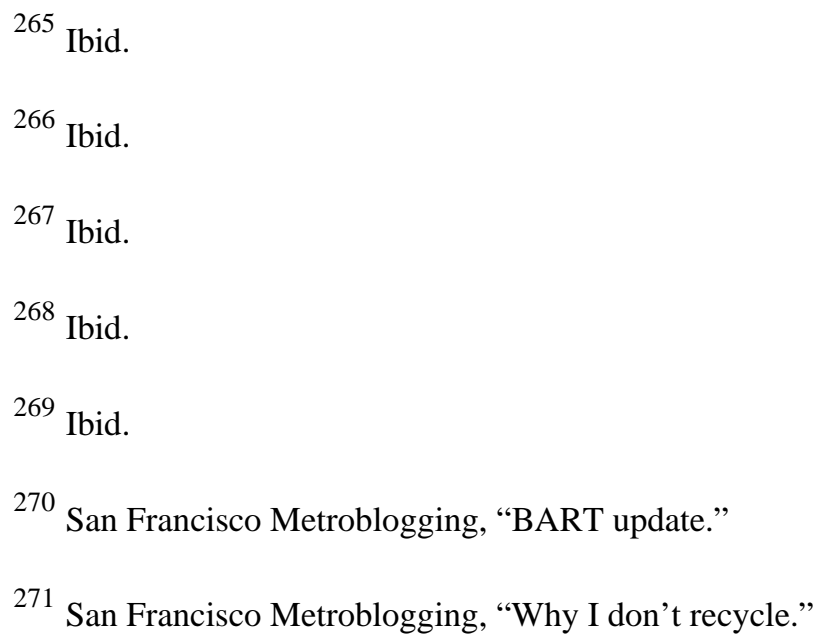


Many San Francisco-based writers shared an affinity for Beat Poet culture, noting developments of a museum for the era's literary movement. In addition, one post mused on the public display of Jack Kerouac's On the Road manuscript.

"When Jack Kerouac, in the spring of 1951, sat at his typewriter and wrote On the Road he did not want to slow down long enough to even put in new paper,” one blogger noted. “Jack improvised by typing it on a roll of pasted together paper."272

The writer, however, did not highlight the obvious parallel between Kerouac's manuscript and the modern blogosphere. Few bloggers "slow down long enough to even put in new paper,” writing frequently and fervently, often without pausing for editing. Perhaps San Francisco resident and fellow citizen journalist Barry Parr could qualify for this description.

\section{Coastsider.com}

Parr, a Bay Area blogger, runs a tiny citizen journalism outfit, coastsider.com. The hyperlocal encompasses news occurring along the San Mateo County coast. (He defines his site’s coverage as Half Moon Bay, El Granada, Moss Beach and Montara). ${ }^{273}$ He describes his site, in that, "We encourage readers to post stories that they have a personal interest in, whether they think they can add something new to the conversation, or want to ask questions.",274

\footnotetext{
272 San Francisco Metroblogging, “The Manuscript is on the Road.”

273 Coastsider, “About Coastsider,” [Accessed online 3 January 2006], http://coastsider.com/more/28 $0 \_10$ _ 0 M/.

274 Ibid.
} 
A former newspaper writer who worked alongside Gillmor at the San Jose Mercury News, Parr runs the site from his home in Montara, California. Ultimately, he hopes to turn a profit this year through local advertising.

Although Parr's only formal training was a high school journalism course, he says his blog routinely scoops the local weekly newspaper, the Half Moon Bay Review. ${ }^{275}$ Parr says he particularly outpaces the paper on city council stories, as the governmental body meets hours after the weekly appears on newsstands, he says. Therefore, an entire week passes before city council stories appear in print. And like backfence.com, Parr regularly publishes a so-called "Sheriff blotter," which encapsulates crime in the San Mateo area.

Yet Parr's stories branch beyond traditional journalism into the realm of political advocacy. Parr clearly marks his opinionated content as "editorial” or "letter to the editor," which is separated from his fact-based news stories. One exemplar, a post by a guest columnist, rallied against local government scrapping the region’s planning commission. In December 2005, he also extensively reported on a local election recount effort for Half Moon Bay City Council candidates.

Unlike bayosphere.com, individuals are not required to use their own names to post, as some place content on the site using pen names. Members still must register with the site, however, by providing a valid e-mail address. ${ }^{276}$ Individuals must also submit to the site’s Terms of Use policy. Despite Parr's vigor for user-driven content, few volunteers have contributed to his site, he says.

275 Barry Parr, interview by author, notes, telephone interview, 25 January 2006.

276 Coastsider, “Member registration,” [Accessed online 3 January 2006], http://coastsider.com/members/register.php. 
In early 2006, Parr issued a correction for one of his stories, a rarity in the blogosphere. $^{277}$

"I did make some rookie mistakes - like taking press releases at face value," Parr told The San Francisco Chronicle. "And real simple stuff like learning to call people and ask questions. But once I started doing that, it became clear."278

${ }^{277}$ Coastsider, "This is the last week to apply for one of two open SamTrans board positions.” 278 Ibid. 


\section{FINDINGS: HYPERLOCAL MEDIA}

From the aforementioned rudimentary hyperlocal experiments on both coasts, a myriad of lessons have emerged regarding the respective roads toward a citizen journalism site's success or failure. While some sites, such as backfence.com, have featured a steady stream of user-driven content, other outlets such as bayosphere.com have devolved into desolate virtual ghost towns.

In the pages that follow, we will examine the prerequisites necessary for citizen media to thrive among the current online landscape. The research will investigate the incongruence regarding East and West Coast hyperlocal media and will suggest a set of best practices for possible new media practitioners.

As a caveat, it should be noted that the blogosphere evolves with enormous rapidity. Therefore, the researcher will supplement the findings contained herein by hosting an online blog, which can be accessed at http://universityjan.livejournal.com.

\section{Building a community}

"Tools matter, but they're no substitute for community building."

- Dan Gillmor ${ }^{279}$

Establishing a hyperlocal is simple.

Attracting talented citizen journalists and sustaining illustrative content presents another obstacle altogether.

Metroblogging’s Sean Bonner says seeking citizen journalist content submissions remains the most challenging facet of managing his online hyperlocal network. ${ }^{280}$

\footnotetext{
279 Bayosphere.com, "From Dan: A Letter to the Bayosphere Coummunity” [Accessed online 24 January 2006], http://bayosphere.com/blog/dan_gillmor/20051228/bayospheres_future.

${ }^{280}$ Sean Bonner, interview by author, transcript, telephone interview, 20 January 2006.
} 
Reflecting on his first foray into grassroots journalism, citizen media pioneer Dan Gillmor agreed, stating that community building should rank as priority number one for hyperlocal practitioners. He cited the lack of camaraderie expressed on bayosphere.com as one of his largest failings. "You need community building and a lot of hand holding to help people understand why they're there and why they should care,” he says. ${ }^{281}$ Gillmor says he's yet to identify the simplest method to target would-be citizen journalists for participation. So his solution is to "try everything.,282

Backfence.com's Mark Potts has tried virtually everything to acquire postings from grassroots journalists. To raise its profile in the Washington, D.C. suburbs, backfence.com sponsored Little League teams. ${ }^{283}$ In winter 2005, the site offered free tshirts for first-time posters. ${ }^{284}$ Months later, Potts and his team unveiled a new promotion, offering \$5 coffee gift cards in exchange for posting five news stories. Banner ads on the site’s homepage enticed visitors to “Make 5 Posts on Backfence. Get a \$5 Specialty Coffee Card Free!”285

But backfence.com isn’t just placing its bets on a journalism-for-coffee business model. The java-infused promotion is part of a holistic approach to augmenting

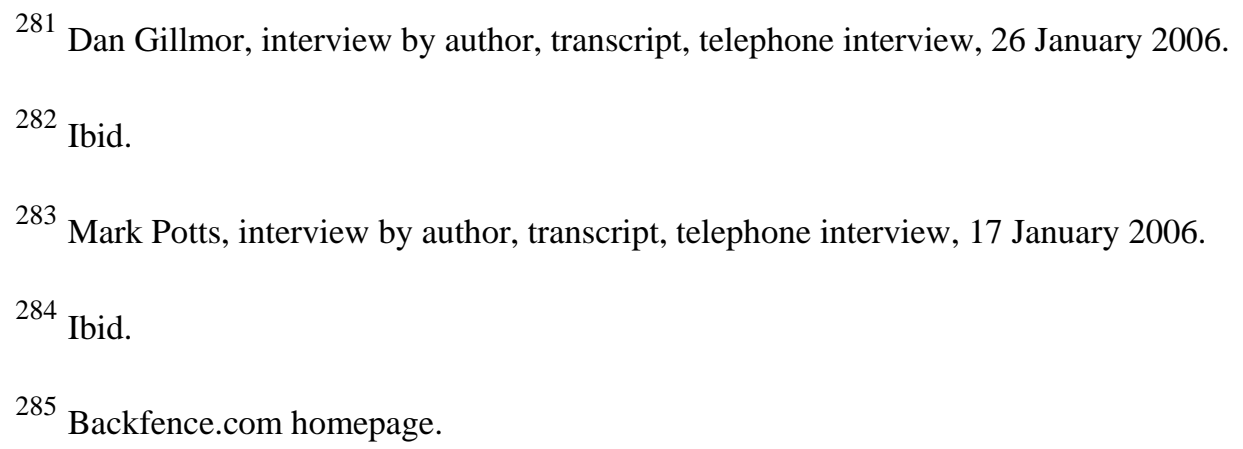


backfence.com's potential media producers and consumers. Potts says that "strong community identification” is imperative to a hyperlocal's success. ${ }^{286}$

"By far, it's the most critical thing you can do," Potts says of community development. "People who are very proud to live where they live and identify strongly with it. They tend to care more about what goes on in their town, therefore, they tend to participate more... We think there's examples out there of people who tried to do this, sort of a 'If you build it; they will come,' and people don't come. You just can't put these things up and hope someone will show up. You really have to get involved in the community with people who know the community...Y You know, just going to community fairs and handing out literature - just generally getting the site out there. And that in turn creates viral growth, as people in turn start passing the word around. But you've got to start somewhere.”

Potts emphasizes his own ties to the community. His profile on backfence.com references his status as a long-term resident, as he has lived in the Washington area for more than 30 years. ${ }^{288}$ He currently resides in Falls Church. Potts adds that he "is a connoisseur of local restaurants and a proud holder of season tickets to the Washington Nationals. ${ }^{289}$ Potts’ partner, Susan Defife, notes in her biography that: "She has been active in many local community and business groups, ranging from serving as Vice Chair of the Northern Virginia Roundtable to being Den Mother for her son’s Cub Scout troop and Cookie Mom for her daughter’s Girl Scout troop."290

Beyond reinforcing their own dedication to the community, the pair tapped into local parent-teacher organizations and civic groups to gain support for their venture. Potts

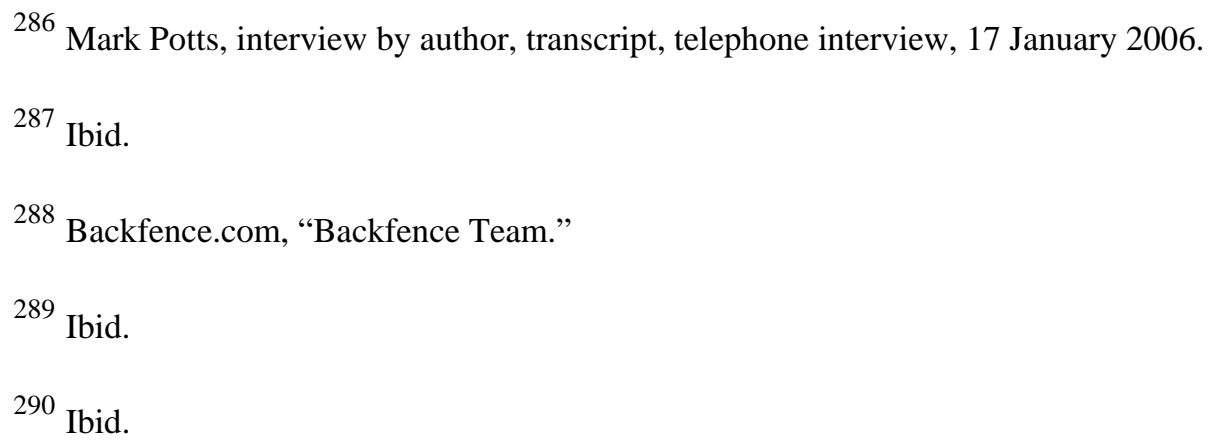


started by assembling a team of community leaders who solicited stories and registered first-time posters. $^{291}$

Many believe backfence.com has been relatively successful in its short tenure on the net because its communities are narrowly tailored. In that sense, the founders targeted small, suburban pockets rather than trying to blanket the entire Washington, D.C. metropolitan with a single citizen journalism site.

Grubisich suggests that Bayosphere’s ambitious aim to encompass the entire Bay Area may have been an overtly aggressive one targeting too many potential users. ${ }^{292} \mathrm{He}$ notes that virtual communities that have been successful with hyperlocal media have focused on very small towns and suburbs, not a sprawling urban metropolis like San Francisco. $^{293}$

In addition, the communities targeted by backfence.com were largely homogeneous. Each hyperlocal market encompassed a roughly equal population with similar median income and ethnic diversity. Nevertheless, Potts hesitated to generalize the demographics of his backfence.com posters, although he contends community members are young. ${ }^{294}$ In a previous interview, Potts had defined that broadband penetration in affluent, younger communities would be the tipping point for hyperlocal growth. $^{295}$

\footnotetext{
${ }^{291}$ Mark Potts, interview by author, transcript, telephone interview, 17 January 2006.

292 Grubisich, "What are the lessons from Dan Gillmor's Bayosphere?”

293 Ibid.

${ }^{294}$ Mark Potts, interview by author, transcript, telephone interview, 17 January 2006.

${ }^{295}$ J-LOG, “Q\&A: Mark Potts of Backfence.com,” [Fall 2005], http://www.mallasch.com/journalism/article.php?sid=1184.
} 
The target backfence.com user likely has school-age children, owns property and is technologically savvy, Potts says. ${ }^{296}$ In that notion, perhaps backfence.com achieves gemeinschaft. Nevertheless, he predicts that future backfence.com communities may be ruled by high school teens, while others may be populated by older members. ${ }^{297}$ "People who have a laptop screen in their kitchen that's always on; they're always checking the web,” Potts said. “That sort of behavior...that's the sort of market we're after. We're looking for soccer moms and soccer dads.”298

Bonner suggests his network boasts a wide demographic, as users range from teenagers to senior citizens. ${ }^{299}$ "Our readership kind of mirrors that,” Bonner says. "We certainly have a huge number of authors and readers who are sort of in the 20s and 30s, but we're all over the place really, so I’m not too concerned with it. „300 Gillmor says he couldn't locate a common thread among bayosphere.com users. ${ }^{301}$

With the demographics in mind, Potts hired like-minded community managers with long-term ties to the geographic community - individuals who had called the Washington, D.C. suburbs home since high school - to promote the site. "I call them my virtual city editors, getting reporters to work for them and post,” Potts says. ${ }^{302}$

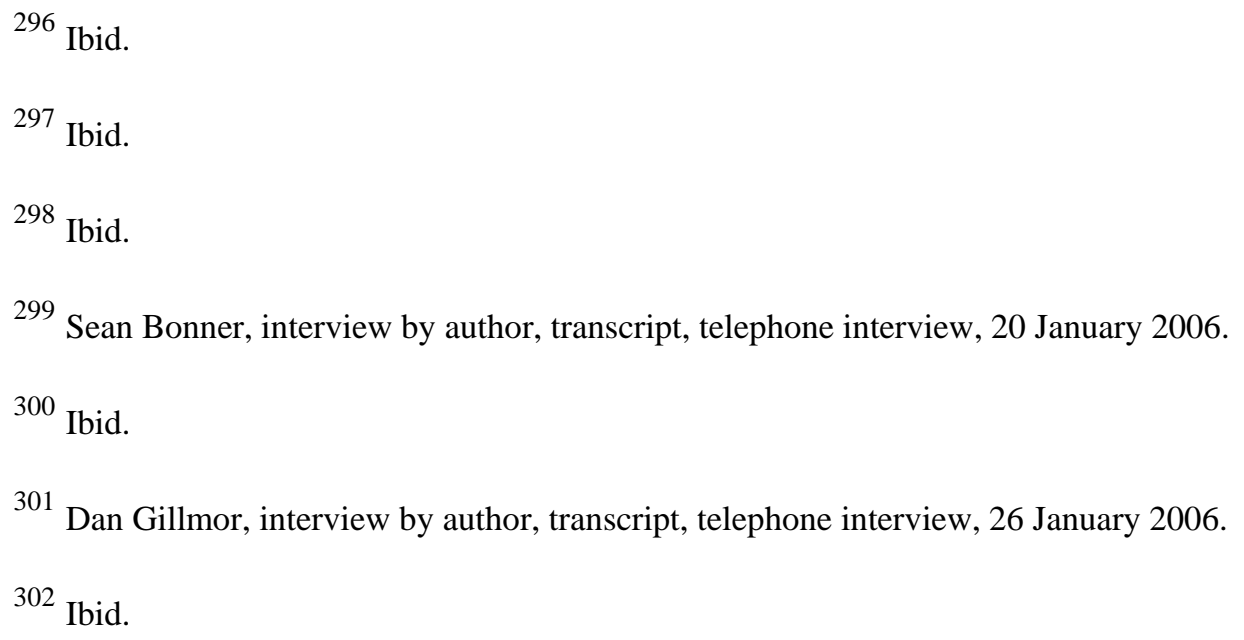


But the virtual city editors cannot drive the site’s content alone, he alleges. A citizen journalism community will fail with pure top-down editorial direction, Potts says. Rather, amateur reporters must set their own agenda for the hyperlocal if it is to be successful. Potts says editors should not make remote decisions, but rather the community should be permitted to exist independently, if possible. ${ }^{303}$ Bonner agrees, in that, "We learned right early on that trying to impose our thing into a city where we thought we should be was a bad idea.”304

Yet, in a missive to the bayosphere.com community, Gillmor expressed his belief in strong editorial oversight. He dissents with other hyperlocal practitioners in the level of oversight required for active participation. He says virtual communities need "pretty strong guidance about what they want it to be.”305 And some hyperlocals need guidance to build a broad-ranged, demographically diverse community. Gillmor’s argument parallels McQuail, who posits that individuals will turn to the media for gatekeeping functions. $^{306}$

But sometimes that community is not confined to cyberspace. Potts wouldn't rule out the possibility that Backfence users from the virtual community may follow a cue from Howard Dean's online camp, and converge in the physical community. "It's not

\footnotetext{
303 Ibid.

${ }^{304}$ Sean Bonner, interview by author, transcript, telephone interview, 20 January 2006.

305 Dan Gillmor, interview by author, transcript, telephone interview, 26 January 2006.

${ }^{306}$ McQuail, McQuail’s Mass Communication Theory, 120.
} 
our intent, but it wouldn’t surprise me at all if it happens,” Potts said. ${ }^{307}$ Many likeminded bloggers on Bonner’s network have developed real-world kinship since joining the Metroblogging community, he says. "I mean, these are people [who] under prior circumstances wouldn't have had any interaction, but because they're all, they're part of this, you know, blogging family,” Bonner said. "You know, they’re all friends.”308 In most cities, the Metroblogging citizen journalists gather once a month for dinner and discussion. ${ }^{309}$ "I would say probably every city there's people who write for the site who hang out together and know each other before they start contributing to the site.”

We will now examine how editors control such site contributions.

\section{Gatekeeping and editorial control}

"There's a huge amount of discomfort with the idea that stuff is not edited and it just goes up there. There's no central gatekeeper, and that really makes editors...well, it just gives them hives."

- Mark Potts ${ }^{310}$

Backfence.com’s community rules remind registered users to "Please treat everyone as if they were your friendly next-door neighbor.”311 But not all rhetoric posted on the hyperlocal would qualify as friendly front porch dialogue. Sometimes the site's editors must intercede and monitor the online discussion.

\footnotetext{
307 Mark Potts, interview by author, transcript, telephone interview, 17 January 2006.

308 Sean Bonner, interview by author, transcript, telephone interview, 20 January 2006.

309 Ibid.

${ }^{310}$ Mark Potts, interview by author, transcript, telephone interview, 17 January 2006.

311 Backfence.com, “Community Rules.”
} 
The site’s community agreement enumerates that "virtually all content...is created by members.”312 The legal disclosure also acknowledges Backfence’s editors rarely change information on the site, and therefore, the proprietors cannot assure the veracity of accounts posted on the site. ${ }^{313}$ Although the legalese document establishes the right for editors to remove and screen content from the site, Potts said posts are rarely altered.

"We want to keep ourselves out, keep our personalities out of it, let the community say and let them take ownership and let them have it be what they want it to be,” Potts says. ${ }^{314}$ He argues implementing editorial controls defeats the purpose of a user-driven community. "We see our site as a free forum to let people tell us what's important,” he said. “People aren’t dumb. People know stuff. And if someone posts something that's completely off the wall, someone's going to flag it and say, 'This isn't what happened, I was there,' and will resolve that issue and bring it up.” 315

According to Potts, only a handful of posts have been removed. The first rejected message forwarded a "really, really nasty" argument surrounding a Little League game, he notes. Potts identified the pejorative thread and asked his content manager to remove it. When the Little League commissioner contacted Backfence the following day to find out the poster's identity, Potts refused to identify the individual.

\footnotetext{
312 Backfence.com, “Community Agreement.”

${ }^{313}$ Ibid.

${ }^{314}$ Mark Potts, interview by author, transcript, telephone interview, 17 January 2006.

${ }^{315}$ Ibid.
} 
Without any editorial prompting, he also received two warning messages from other community members regarding the post. Any user can complete a misconduct report if they find content that is inappropriate or offensive. The reports, which are reviewed by the site’s content manager on a daily basis, are rather infrequently used, Potts says. The notion that the hyperlocal community is somewhat self-policing would seem to satisfy one of Wood and Judris’ components for community existence. The authors posit that community members “develop a sense of common purpose/interest for which they assume mutual responsibility."316

In another recent case, Backfence editors removed a Yellow Pages posting. A writer had personally attacked an owner of a local business, Potts said. "We told them 'You know, you can’t attack a person,’” Potts said. “’You can go after a business. You can say whatever you want about a business. But don’t go after a person.”’317 Potts permitted the writer to repost the information with the personal content omitted, he said.

Parr reviews each post submitted to his small, Bay Area hyperlocal. On his site, Parr writes:

We will review stories for consistency with our editorial policy. We will remove articles and comments that are spam, false, disrepectful, or illegal. We'll use our best judgement, but it's at our discretion. As for our posters, we recommend writing about others the way you'd want them to write about you. Be respectful and fair. ${ }^{318}$

\footnotetext{
${ }^{316}$ Wood and Judris, Conversations on Community Theory, 12.

${ }^{317}$ Mark Potts, interview by author, transcript, telephone interview, 17 January 2006.

318 Coastsider, “About Coastsider,” [Accessed online 3 January 2006], http://coastsider.com/more/28_0_1_0_M/.
} 
Bonner takes an absolutist approach to gatekeeping his Metroblogging

communities. He asserts he wouldn’t step in as an editor, even if the content were deemed inappropriate or offensive. He explains that censoring blogs is antithetical to their very nature. ${ }^{319}$

"I think that the power of blogs is that they're unedited. You're getting that writer's voice without going through any filters. If I started going through and thinking, that's not appropriate or whatever, that would defeat the whole thing and the whole network would lose credibility in a second.”320

As a control, each hyperlocal site on Bonner's network maintains a listserv among the citizen journalists. If any posts disturb the blogging community, then the listserv is the first place to discuss the questionable content. ${ }^{321}$

Gillmor says the issue of hyperlocal credibility will need to be addressed for the medium to thrive. "If you assume ubiquitous networks and people having the ability to do their own media, I think we end up with vast amounts of media and what we're lacking, among other things, are tools to separate the good stuff from the bad stuff,” he says. ${ }^{322}$ In his gatewatching theory, Bruns has echoed Gillmor's statements, predicting the next generation of journalists will act not as news producers, but as "librarians” who will direct users toward content. ${ }^{323}$

\footnotetext{
319 Ibid.

${ }^{320}$ Sean Bonner, interview by author, transcript, telephone interview, 20 January 2006.

321 Ibid.

322 Dan Gillmor, interview by author, transcript, telephone interview, 26 January 2006.

323 Bruns, Gatewatching, 16.
} 
Even without editors to filter information, some of the "good stuff" is beginning to appear online, critics suggest. Some academics have extolled select postings on backfence.com, which provided incredibly detailed arguments. The posts even used government documents, zoning ordinances, police reports and property records. “There’s some pretty amazing evidence being brought back and forth,” Potts said. ${ }^{324}$ And even though Potts once told The Washington Post's Howard Kurtz that the site's content “is not Woodward and Bernstein stuff,” he admits that users are beginning to conduct lowlevel, document-centric investigative journalism on the site. ${ }^{325}$

In an interview with the researcher, Potts clarified his statements printed in The Washington Post. "It's not Woodward and Bernstein stuff, to the point that it's not professional journalism," he said. "Whatever that means. But it turns out people in the community know stuff, and they're passionate about the stuff, and they're smart about the stuff, and they go out and share it with their neighbors.”326

Potts highlights a post that appeared online late last summer regarding a real estate transaction. MSM had reported on the sale of property adjoining Dulles Airport. Within 24 hours, one backfence.com poster had completed an exhaustive financial analysis of the land deal. ${ }^{327}$ The financial data surpassed MSM reports, Potts said, beating The Washington Post and other metro news organizations to the story.

\footnotetext{
324 Mark Potts, interview by author, transcript, telephone interview, 17 January 2006.

325 Kurtz, “This Just in, from the Guy Next Door,” C01.

${ }^{326}$ Mark Potts, interview by author, transcript, telephone interview, 17 January 2006.

327 Ibid.
} 
Despite such promise-filled glimpses into the new medium, Gillmor expressed doubt in the potential for truly free and unfettered citizen journalism. "If you're trying to achieve journalism in the sense that I know it, then hands-off, I think, is not going to work or at least not going to be easy," Gillmor said. "It's not what I would recommend. I think people need and want guidance and ideas and assistance.”328

\section{Future of hyperlocal media}

"We don't want to build ghost towns; we want to build these things so that they work and they're popular."

- Mark Potts ${ }^{329}$

Potts, for one, hardly imagines MSM's demise. He doubts that hyperlocal media will ever entirely replace traditional journalism. ${ }^{330}$

Nevertheless, MSM has started to borrow from hyperlocal sources, he alleges. For instance, Potts alleges instances in which The Washington Post lifted story ideas directly from the backfence.com community. In particular, he claims a Post feature profiling a grocery store closing was only covered by the paper after prolonged speculation embroiled the site’s discussion boards. "When I saw the story, I thought, 'Gee, what a coincidence,"’ Potts said. $^{331}$

Although the researcher cannot confirm or deny Potts’ suspicions, hyperlocal media would theoretically present a fruitful testing ground for enterprise reporting. Potts, a former reporter himself, says he has no problems with MSM journalists visiting his site

${ }^{328}$ Dan Gillmor, interview by author, transcript, telephone interview, 26 January 2006.

329 Mark Potts, interview by author, transcript, telephone interview, 17 January 2006.

330 Ibid.

331 Ibid. 
for inspiration. In fact, one local reporter posted stories on Backfence that she couldn’t get into her publication. ${ }^{332}$ Her newspaper editor had rejected the story, which was too lengthy. ${ }^{333}$ Analogously, sometimes Metroblogging stories have mysteriously ended up in MSM, including The New York Times, Bonner alleges. ${ }^{334}$

As new media practitioners allege that MSM outlets are increasingly borrowing story ideas from grassroots media sites, traditional news corporations have yet to fully embrace hyperlocal technology. Potts and Bonner foresee MSM's forthcoming entry into the realm of open source news. Gillmor heralds that MSM "should be the chief doers" of hyperlocal expansion. ${ }^{335}$

Yet newspapers editors and television broadcasters have been slow to formulate citizen journalism projects.

Why the delay?

The wheels of change in large corporations often grind very, very slowly, Potts asserts.

In late 2005, The State - Columbia, South Carolina's paper - launched a citizen journalism website. ${ }^{336}$ The printed publication recruited 25 local bloggers to act as chief content providers. ${ }^{337}$ Most posts on the site will not be edited, even though the paper

332 Ibid.

333 Ibid.

${ }^{334}$ Sean Bonner, interview by author, transcript, telephone interview, 20 January 2006.

335 Dan Gillmor, interview by author, transcript, telephone interview, 26 January 2006.

336 Jay DeFoore, “'The State' (Columbia, S.C.) Launches Community Blog, Citizen Journalism Push,” (1 September 2005): Accessed through Lexis-Nexus database.

337 Ibid. 
planned to hire a content manager for the hyperlocal's oversight. ${ }^{338}$ Likewise, in September 2005, The Austin American-Stateman established a similar website for extensive reader interaction. ${ }^{339}$ The paper targeted University of Texas students and local musicians as the primary contributors to the community blogs. ${ }^{340}$

(Despite the innovative attempts by moderate-sized newspapers to explore the blogosphere, the citizen journalism attempts in Columbia and Austin have not been overwhelmingly successful as of this writing).

Even metropolitan papers of record, such as the Los Angeles Times, which attempted entry into the blogosphere, also have struggled to reach an audience. As previously mentioned, the site's wikitorial utterly failed and was abandoned within weeks. All posts on the paper’s blog were edited, a practice that Bonner asserts defeats the purpose of blogging altogether. "Their writers are sending things in, going through an editor,” he says. "I mean, it’s sort of clear that it’s not a blog. And they're kind of just using that word."341

Potts, Bonner, Gillmor and Parr agree that no one has unlocked the secret formula for a hyperlocal's instant success. However, Bonner believes entrepreneurs, rather than established media behemoths, will take the initial bold step further into virtual

\footnotetext{
338 Ibid.

339 Jay DeFoore, “Austin American-Statesman Launches Community Blogs,” (14 September 2005): Accessed through Lexis-Nexus database.

340 Ibid.

341 Sean Bonner, interview by author, transcript, telephone interview, 20 January 2006.
} 
community development. “And I don’t know why local news isn’t catching on along those lines,” Bonner said. "I can’t imagine that it will continue not to catch on.”342 Potts agrees that independent publishers unassociated with MSM will adopt hyperlocalism before traditional journalists do. In the coming years, he anticipates several Backfence-like companies will emerge throughout the country. As the sites establish readers and contributors, Potts predicts that hyperlocal chains will form. Akin to the newspaper industry, where corporations such as Knight Rider and Gannett dominate the print landscape, a handful of companies will unite hundreds of hyperlocal sites under common ownership.

Despite concentrated ownership, Potts anticipates little competition between hyperlocal companies in designated media markets. "We’ll just kind of split up the world,” Potts said. ${ }^{343}$ In essence, Potts doubts two hyperlocal companies can function side-by-side in the same town or region. "If I've got all my stories and kids' pictures and everything else on Backfence, I'm not going to get up one morning and switch over to Platform B,” Potts said. ${ }^{344}$

Yet many independent, "Platform B” entries into the hyperlocal media environment are beginning to challenge backfence.com. Among the scenic Rocky Mountains, another promising hyperlocal, yourhub.com, was unveiled in February 2006. The site, a partnership between the Denver Newspaper Agency and The Rocky Mountain

${ }^{342}$ Ibid.

${ }^{343}$ Mark Potts, interview by author, transcript, telephone interview, 17 January 2006. 344 Ibid. 
News, allows users to add news stories, post photos or start blogs. ${ }^{345}$ Users from 42

Colorado-based communities can add content. ${ }^{346}$ The founders of the site plan to expand to nine other metropolitan areas in $2006 .^{347}$

Newsvine.com recently launched an invitation-only beta in the Pacific

Northwest. ${ }^{348}$ The start-up, founded by former Disney and ESPN writers, allows users to view Associated Press wire copy, as well as publish their own stories, blogs and photos. ${ }^{349}$ The presence of wire copy acts as a check-and-balance on user-driven content, the site's owner believes. ${ }^{350}$

Newsvine is changing the hyperlocal paradigm in one essential manner: profit sharing. Contributors will receive a portion of the site's ad revenue, a fact that Gillmor strongly believes is essential toward building a strong citizen journalism community. ${ }^{351}$ Another new outfit, ChiTownDailyNews.org, which was founded by a former Chicago Tribune reporter, will offer regular stipends to website contributors. ${ }^{352}$ Individuals who submit stories regularly will receive $\$ 25$. Some writers will receive $\$ 100$ for "stories of

\footnotetext{
345 PR Newswire, “YourHub.com Launches National Syndication,” [Accessed online 15 February 2006]: Accessed through Lexis-Nexus database.

346 Ibid.

347 Ibid.

348 Stephen Bryant, “Journalism 2.1? A new site tweaks the grassroots formula” USC Annenburg Online Journalism Review [Accessed online 9 February 2006], http://www.ojr.org/ojr/stories/060129grubisich/. 
the month., ${ }^{353}$ Gillmor suggests that incentives will grow more important as hyperlocalism competition develops on the Web. ${ }^{354}$ In providing financial compensation for amateur journalism, ChiTownDaily News adviser Geoff Dougherty hopes bloggers will contribute stories not covered by The Chicago Sun-Times or Chicago Tribune. ${ }^{355}$ In fact, he hopes to find "neighborhood correspondents" for each of the city's 50 zip codes. ${ }^{356}$ (And in an odd synergistic twist, he's also working with a local theatre company to produce video op-ed satires of local politicians for posting on the site). ${ }^{357}$

So is paying citizen journalists the best practice for building a virtual community? Hyperlocal practitioners believe that constructing an effective business model remains essential for future hyperlocal growth.

“There’s sort of a big question hanging out over there, which is, what's the business that people do?” Gillmor asked. "And assuming there is a business, how will, who will find a way to make sure the contributors will share in the rewards??358

In mid-January 2006, Potts said backfence.com will start accepting advertisements, which will hopefully enhance the site's profitability. Furthermore, Potts plans to hire additional staff outside Washington, D.C. as Potts aims to expand the

\footnotetext{
353 Ibid.

${ }^{354}$ Bayosphere.com, "From Dan: A Letter to the Bayosphere Coummunity.”

355 DeFoore, "Hyper-Local Chicago News Site to Pay 'Citizen Journalists.”

${ }^{356}$ Ibid.

${ }^{357}$ Ibid.

${ }^{358}$ Dan Gillmor, interview by author, transcript, telephone interview, 26 January 2006.
} 
backfence.com brand nationwide. ${ }^{359}$ "We've got hundreds of e-mails from all over the country saying 'When can backfence be here?’” Potts said.

In 2006, Potts also plans to introduce citizen video and audio capabilities.

Bandwidth would be limited, but Potts envisions his site will allow proud parents, for example, to share footage of Little League games over the net.

“Like, here’s my kid’s winning hit at the game last night,” Potts envisioned.

"Wouldn’t that be cool?"360

359 Mark Potts, interview by author, transcript, telephone interview, 17 January 2006.

360 Ibid. 


\section{CONCLUSION AND SUGGESTIONS FOR FUTURE RESEARCH}

If Mark Potts were to be born in 2020, would his entry into the world of journalism be an early morning paper route?

Admittedly, research from the Pew Internet and American Life Project demonstrates more individuals are accessing news and information online. Younger news consumers, especially, are increasingly reliant on net news. Consequently, printed circulation levels are plunging quarterly.

So is it time to sound the death knell on neighborhood news in America? As hypothesized, the researcher’s findings unveiled that hyperlocal news coverage rarely encompassed breaking news or sustained investigative reporting (although glimpses of low-level, document-centric news analysis were present). The online posts, writings that Potts defined as "letters from the suburbs," effectively paint portraits of salient issues. Yet there are few suburban postcards sent from the virtual community. In short, hyperlocal participation has yet to achieve critical mass.

The present study posits the few virtual community members do aggregate into online communities bound together by ideological homogeneity. Hyperlocal users, who self-police inappropriate and inaccurate content, seemingly bear mutual responsibility for the greater good - a requisite for community formation. As the majority of hyperlocal posts examined did not engage in flaming behaviors, it could be further forecasted that users respect one another - another attribute defining community.

Nevertheless, the hyperlocal sites examined were rather homogeneous and appeared to instill notions of gemeinschaft among members. Future researchers could interview hyperlocal contributors to assess the bridging or bonding elements present in 
hyperlocal discourse. A broader comprehension of hyperlocal media could be enhanced if the current research's top-down view of hyperlocal media could be complemented with a “blogger-on-the-street” perspective.

Citizen journalism communities have yet to achieve levels of heightened interactivity, this study posits. While many average, amateur journalists are penning blogosphere missives, very few are forwarding elaborate discourse. In fact, some grassroots bastions resembled virtual ghost towns - abandoned settlements on the online frontier that resemble aging remnants of the Wild West, not the vibrancy of the World Wide Web.

Therefore, attracting and sustaining site contributors presents the most significant challenge to a young online community, the research suggests. Moderately successful hyperlocals, such as backfence.com, have dedicated extensive efforts to surveying and rallying the community to entering the cyberspace forums. Without real world advocacy, communities such as bayosphere.com and coastsider.com struggled not only in finding an audience, but in locating citizen journalists as well. Clearly, hyperlocal practitioners must develop a bridge between the virtual and real-world communities.

While hyperlocal practitioners possess varying convictions as to the level of online gatekeeping necessary for reliable content, the research notes that citizen journalists can produce meaningful and illustrative content without strong editorial guidance. Hyperlocal sites vary as to the level of permeability for citizen journalists to enter the respective online communities illustrated herein. Nevertheless, such trailblazing “neointermediaries” have created content designed to reach a mass audience. 
The veracity and trustworthiness of the user-driven submissions has yet to be established. As suggested in the literature, average Americans negatively view press trustworthiness. Therefore, additional research should be conducted on how hyperlocal practitioners assure users that the hyperlocal news can be considered accurate and reliable.

Whether MSM will transform the devolved blogosphere remains unclear. Although numerous newspapers have experimented with rudimentary hyperlocalism, few MSM-sponsored test beds have been deemed successful. As technology continues to outpace MSM's hyperlocal presence, one could theorize it will be even more difficult for traditional journalists to adapt to the blogosphere. Future ethnographic case studies profiling newspapers such as the Greensboro News \& Record could reveal the insider perspective behind media moguls who may influence grassroots media in the years to come. Ultimately, as with all other historic media, profitability (or lack thereof) will likely act as the Northern Star to guide whether MSM expands its hyperlocal presence or deserts the blogosphere altogether.

Clearly, hyperlocal media does not resemble textbook journalism. Forget inverted pyramid style, blind leads and nut grafs. Yet without intricate knowledge of the craft of journalism, citizen journalists have crafted a new breed of neighborhood news.

"It's possible that any one of us might do journalism at any moment, and I think we should be helping people who might participate,” Dan Gillmor says. ${ }^{361}$

One never knows - for at this very moment, a neighbor could be practicing grassroots journalism in your own backyard.

361 Dan Gillmor, interview by author, transcript, telephone interview, 26 January 2006. 


\section{CODA}

In mid-January 2006, backfence.com founder Mark Potts envisaged the formation of hyperlocal chains that would unite the citizen media realm under common ownership. Consolidation would mark the industry, he said. ${ }^{362}$

With a terse paragraph post added to his site on December 28, 2005, bayosphere.com founder Dan Gillmor foreshadowed that his site could change ownership. ${ }^{363}$

Both statements would prove powerfully prophetic.

\section{On April 17, 2006, backfence.com publicly announced its acquisition of}

\section{bayosphere.com.}

In a posting on his blog, Gillmor said that he decided to merge with backfence.com after conferring with his partner, Michael Goff, and Bayosphere’s original investing team. ${ }^{364}$ (In return, Bayosphere’s investors will become shareholders in backfence.com). ${ }^{365}$

Although the fledgling site struggled for both financial and community support, closing down Bayosphere was never considered as an option, Gillmor wrote. ${ }^{366}$ He stated his investors were "truly pleased with this move,” calling backfence.com "genuine

${ }^{362}$ Mark Potts, interview by author, transcript, telephone interview, 17 January 2006.

363 Bayosphere.com, “Bayosphere’s Future,” http://bayosphere.com/blog/dan_gillmor/20051228/bayospheres future.

364 Dan Gillmor, “Welcome to Backfence,” [Accessed online 18 April 2006], http://sf.backfence.com/bayarea/showPost.cfm?mycomm=BA\&bid=2232.

365 Anick Jesdanun, “Internet Startup Acquires Bayosphere,” The Associated Press, 19 April 2006.

${ }^{366}$ Dan Gillmor, "Welcome to Backfence.” 
pioneers in the citizen media field.”367 Backfence.com co-founder Susan Defife returned the compliment, telling the Associated Press that joining forces with Gillmor was a perfect fit to expand Backfence westward. She stated that Gillmor's vision combined with Backfence’s community building tools would revolutionize citizen media. ${ }^{368}$

Now, web browsers are redirected to the site's new, temporary URL: sf.backfence.com/bayarea. (An archived edition of the original bayosphere.com was still accessible as of April 22, 2006. However, many of the hyperlinks footnoted in this thesis may be inactive in the near future). A banner ad reminded visitors that, "Bayosphere.com is now backfence.com!”

This spring, backfence.com plans to launch its first San Francisco hyperlocal from the remnants of the original bayosphere.com network.

In his latest blog posting, Gillmor expressed one of bayosphere.com’s largest failings was lacking a proximate focus. ${ }^{369}$ So rather than replicate Bayosphere’s efforts to encompass all of greater San Francisco, the first hyperlocal community - to be unveiled in May 2006 - will solely focus on Palo Alto, California. An advertisement on the rudimentary site announced plans for hiring San Francisco-based content, marketing and advertising staff.

Gillmor will remain on board as a regular blogger and contributor to the Bay Area hyperlocals. His blog will be incorporated into backfence.com’s Bay Area network. Although he no longer has input into the site's greater business model, Gillmor still hopes

${ }^{367}$ Ibid.

368 Jesdanun, “Internet Startup Acquires Bayosphere.”

369 Ibid. 
to remain an advocate for citizen journalism in his new backfence.com capacity. He will also teach a journalism course next fall.

"Everyone is learning; everyone is experimenting," Gillmor told the San Jose Mercury News. "It’s early days." 370

370 Therese Poletti, “' Citizen Journalism’ Effort for Palo Alto: D.C. Start-Up to Buy Bayosphere Web Site,” San Jose Mercury News, 18 April 2006. 


\section{APPENDIX A: CODING SCHEME}

The following operational definitions were coded in the study's data set according to the parameters established below:

\section{$\underline{\text { Topic }}$}

All threads will be categorized into one of seven topics:

- Seasonal event: Promotion or summary of an event surrounding a holiday or holiday season.

- $\quad$ Arts and entertainment: Previews and reviews.

- Community event: Promotion or summary of an event not surrounding a holiday or holiday season.

- Politics: News regarding local government or governmental bodies.

- Zoning and Development: News regarding commercial or residential development.

- Sports

- Crime

Date

The date of the original posting will be recorded to better organize the research.

\section{Community}

For backfence.com postings, the researcher designated whether the post appeared on the Bethesda, McLean or Reston hyperlocal.

\section{$\underline{\text { Number of replies }}$}

To further gauge the level of interactivity, the researcher examined each original post to see if the author directly solicited feedback from the backfence audience. A reply is defined as providing feedback to an original post.

\section{$\underline{\text { Link to MSM }}$}

A poster provides a hyperlink or references a traditional media news source.

\section{Link to blogosphere}

A poster provides a hyperlink or references a personal home page or blog.

\section{Critical MSM coverage}


A writer expresses a negative opinion of MSM coverage.

$\underline{\text { Public documents }}$

A post includes text, hyperlink or synopsis of an official government document (e.g. zoning ordinance, building permit, police report).

\section{First person POV}

A writer uses first person in the posting.

$\underline{\text { Photo }}$

The original poster contributes a picture.

$\underline{\text { Feedback }}$

The first poster directly solicits feedback from the backfence.com audience.

\section{$\underline{\text { Long-term resident }}$}

Any poster in a given thread references living in the community for 5 or more years.

\section{Community discord}

Subsequent replies to the original thread express a differing viewpoint than the original author's contention.

\section{$\underline{\text { Official reply }}$}

A government official replies to a posting.

\section{Press release}

The original posting was an official press release.

\section{Contact information}

The original poster provided contact information, such as an e-mail address or phone number, within the post's text. 


\section{APPENDIX B: INTERVIEW SCHEDULE}

FOUNDATION:

- How did you start your site?

o Biggest surprise so far?

o Greatest reward so far?

o Hypothesized characteristics for hyperlocal success

- "Main tipping point"

- Affluence

- Well-educated population

- School aged-kids

- Were hypotheses correct?

- Other factors for hyperlocal success?

o How do you define hyperlocal success?

o What challenges (besides financial) came with launching?

o How many employees now?

o Describe a typical day.

USERS:

- Describe a typical user.

o Long-term resident?

o Demographics?

- Concern about demographic homogeneity?

- How many users?

- How encourage contributions?

o Meetup.com potential: Can online community affect geographic community?

CONTENT:

- Popular threads/topics?

o Favorite thread?

o Pejorative posts?

- Page view stats?

EDITORIAL:

- How choose elements for home page?

MSM:

- How ensure trust/credibility?

- Have papers (to your knowledge) developed stories that were first featured on site?

- Will MSM co-opt technologies? If so, how?

EXPANSION:

- Audio/video content?

- Where do you see hyperlocal media in 5, 10, 25 years?

o What role will your site play? 


\section{APPENDIX C: IRB PROTOCOL}

The researcher was granted an exemption from full board review by the College's Institutional Review Board representative, Dr. Diana Knott. The study is classified as a case study/oral history project, and therefore, did not require full board review. In order

to obtain the exemption, the researcher submitted paperwork and a preliminary interview schedule.

As required by IRB protocol, subjects were sent an e-mail cover letter explaining the researcher's intentions. The correspondence explained that the data would not remain anonymous or confidential, and that the subjects' names would be printed with their comments. The researcher also expressed that participants possess autonomy to exit the study at any time, and may refuse to answer any questions asked by the principal researcher. The subjects were also informed that the researcher intended to publish the research publicly.

According to Dr. Ralph Hanson and Lilo Ast, an IRB representative, the content analysis portion of this research did not require IRB approval because it did not contain interaction with live subjects. 


\section{WORKS CITED}

The Associated Press, “Newspaper Circulation Falls Again,” 1 November 2004, [Accessed via Associated Press Wire].

Backfence.com, “Backfence Inc., Leading Hyperlocal Online Citizens’ Media Company, Receives Funding,” [Accessed online 13 October 2005]: http://www.backfence.com/about/index.cfm?page=/press/101205\&mycomm=BE.

, "Backfence Team,” [Accessed online 21 January 2006]: http://www.backfence.com/about/index.cfmpage=/press/team.

, “Community Agreement,” [Accessed online 21 January 2006]:

http://www.backfence.com/about/index.cfm?page=/membeers/commRules\&mycomm=R E.

, “Community Rules," [Accessed online 21 January 2006]:

http://www.backfence.com/about/index.cfm?page=/membeers/commAgree\&myc omm=RE.

Bayosphere.com, "Bayosphere's Future” [Accessed online 3 January 2006]:

http://bayosphere.com/blog/dan_gillmor/20051228/bayospheres_future

, “Bayosphere Journalist Sign-up,” [Accessed online 6 March 2006]: http://bayosphere.com/cjregister

, "Be a Citizen Journalist,” [Accessed online 6 March 2006]:

http://bayosphere.com/be_a_journalist.

, "From Dan: A Letter to the Bayosphere Coummunity" [Accessed

online 24 January 2006]: http://bayosphere.com/blog/dan_gillmor/

20051228/bayospheres_future

, “Why Real Names for Citizen Journalists?” [Accessed online 6 March 2006]: http://bayosphere.com/real_names

Bleyer, William Grosvenor, Main Currents in the History of American Journalism. Boston: Houghton Mifflin, 1927.

Boczkowski, Pablo J., Digitizing the News. Cambridge, MA: The MIT Press, 2004.

Bonner, Sean, interview by author, transcript, telephone interview, 20 January 2006. 
Boogers, Marcel and Voerman, Gerrit, "Surfing Citizens and Floating Voters: Results of an Online Survey of Visitors to Political Web Sites during the Dutch 2002 General Elections.” Information Polity 8 (2003): 17-27.

Brown, Fred, “Citizen Journalism is not Professional Journalism.” Quill 93, 6 (2005): 42.

Bruns, Axel, Gatewatching: Collaborative Online News Production. New York: Peter Lang Press, 2005.

Bryant, Stephen, "Journalism 2.1? A new site tweaks the grassroots formula." USC Annenburg Online Journalism Review [Accessed online 9 February 2006]: http://www.ojr.org/ojr/stories/060129grubisich/.

CBS News, “CBS News Unveils Web Strategy,” [Accessed online 12 July 2005]: http://www.cbsnews.com/stories/2005/07/12/entertainment/main708433.shtml?C MP=ILC-SearchStories.

Coastsider, “About Coastsider,” [Accessed online 7 March 2006]: http://coastsider.com/more/28_0_1_0_M/ , "Member registration," [Accessed online 7 March 2006]: http://coastsider.com/members/register.php

Conan, Neal, “Blogging: A Web Diary Tour.” Talk of the Nation, NPR, 21 June 2004.

Dana, Rebecca, “Blog Chicks Boot Up on Blitzer," New York Observer, 28 September 2005.

Davis, Richard, The Web of Politics. New York: Oxford University, 1999.

De Cindio, Fiorella, et al., "Community Networks: Rules of Behavior and Social Structure.” The Information Society 19 (2003): 395-406.

DeFoore, Jay, “Austin American-Statesman Launches Community Blogs,” [Accessed online 14 September 2005]: Accessed through Lexis-Nexus database.

, "Hyper-Local Chicago News Site to Pay 'Citizen Journalists'," Editor and Publisher [Accessed online 28 December 2005]: Accessed through Lexis-Nexus database.

, "'The State (Columbia, S.C.) Launches Community Blog, Citizen Journalism Push.” Editor and Publisher [Accessed online 1 September 2006]: Accessed through Lexis-Nexus database.

Dorroh, Jennifer, “It’s Like Cable News for Your Neighborhood.” American Journalism Review (June/July 2005). 
Fishbowl DC, “Hyperlocal Site Wins \$3M in Funding.” [Accessed online 19 October 2005]:

http://www.mediabistro.com/fishbowlDC/online_media/hyperlocal_site_wins_3m in_funding_27067.asp.

Gillmor, Dan, interview by author, transcript, telephone interview, 26 January 2006.

We the Media: Grassroots Journalism For the People, By the People. Sebastopol, CA: O’Reilly Media, 2004.

"Welcome to Backfence," [Accessed online 18 April 2006]:

http://sf.backfence.com/bayarea/showPost.cfm?mycomm=BA\&bid=2232.

Glaser, Mark, “The New Voices: Hyperlocal Citizen Media Sites Want You (to Write)!” USC Annenberg Online Journalism Review, 17 Nov 2004, [Accessed online 21 December 2005]: http://ojr.org/ojr/glaser/1098833871.php.

Green, Heather, “Great Online Expectations; Bayosphere wanted to reinvent journalism. Here's how the dream died.” BusinessWeek (20 February 2006): 68.

“'Online Extra: News You Can Use -- and Write; Bayosphere's grand plans may be history, but many more community Web sites have taken its lessons to heart, letting everyday citizens deliver news.” BusinessWeek, (20 February 2006).

Grubisich, Tom, “What are the lessons from Dan Gillmor's Bayosphere?” USC Annenburg Online Journalism Review (29 January 2006): http://www.ojr.org/ojr/stories/060129grubisich/.

Gulf Reston, Inc., “A Brief History of Reston, Virginia,” (1970) [Available online]: http://www.restonmuseum.org/retrospective.html

Henig, Samantha, “Citizens, Participants and Reporters.” Columbia Journalism Review Daily, 8 July 2005, [Accessed online 8 July 2005]: http://www.cjrdaily.org/politics/citizens_participants_and_repo.php

Holley, Joe, “Weekly, Strongly.” Texas Monthly 25, 12 (December 1997): 82.

Horrigan, John et al., “The Internet and Democratic Debate.” Pew Internet \& American Life Project [Accessed online: 27 October 2004]: http://www.pewinternet.org/PPF/r/141/report_display.asp

Jesdanun, Anick, “Internet Startup Acquires Bayosphere.” The Associated Press, 19 April 2006. 
J-LOG, “Q\&A: Mark Potts of Backfence.com.” [Accessed online 2005]: http://www.mallasch.com/journalism/article.php?sid=1184

Johnson, Bobbie, “Online blog watch: Citizen Chain.” The Guardian (U.K.), 30 June 2005: 20.

Johnson, Thomas J. and Kaye, Barbara K., "Cruising is Believing: Comparing Internet and Traditional Sources on Media Credibility Measures.” Journalism \& Mass Communication Quarterly 75, 2 (Summer 1998): 325-340.

Keller, Suzanne, Community: Pursuing the Dream, Living the Reality. Princeton: Princeton University Press, 2003.

Klaidman, Stephen and Beauchamp, Tom L., The Virtuous Journalist. New York: Oxford University Press, 1987.

Klam, Matthew, "Fear and Laptops on the Campaign Trail.” The New York Times Magazine, 26 September 2004: 43-54.

Kurtz, Howard, “This Just in, From the Guy Next Door,” The Washington Post, 13 December 2004, C01.

Lenhart, Amanda et al., "Online Activities and Pursuits.” Pew Internet \& American Life Project [Accessed online 3 March 2004]: http://www.pewinternet.org/PPF/r/113/report_display.asp

Levin, Yuval, “Politics After the Internet.” Public Interest 149 (2002): 91.

Little, Adrian, The Politics of Community. Edinburgh: Edinburgh University Press, 2002.

Los Angeles Times, “Where’s the Wikitorial?” Los Angeles Times, 17 July 2005: http://www.latimes.com/news/opinion/editorials/la-wiki-splash,0,1349109.story.

Macht, Joshua, "New Medium, Old Rules; The On-Line Editor Comes of Age.” The Harvard International Journal of Press/Politics 6, 1 (Spring 2001): 128-131.

MacIntyre, Donald and Kim, Yooseung, “The People’s News Source.” Time 165, 23 (2005): 42.

MacKinnon, Rebecca, "Blogging, Journalism and Credibility: Battleground and Common Ground.” Paper compiled from the Harvard University Conference on Blogging (2005).

McQuail, Denis, McQuail’s Mass Communication Theory. London: Sage, 2000.

Mellow, Muriel, “The Work of Rural Professionals: Doing the Gemeinschaft- 
Gesellschaft Gavotte.” Rural Sociology 70, 1 (2005): 50-69.

Merritt, Richard L., "Public Opinion in Colonial America: Content-Analyzing the Colonial Press.” The Public Opinion Quarterly 27, 4 (Winter 1963): 356-371.

Newhagen, John E., Cordes, John W., and Mark R. Levy, "Nightly@nbc.com: Audience scope and the perception of interactivity in view mail on the Internet." University of Maryland Research [Accessed online 1 December 2004]: http://jnews.umd.edu/johnen/research/nbc.htm

New West Politics, "Denver Media Offering Politicos Free PR Outlet.” http://www.newwest.net/index.php/topic/article/6537/C37/L37

News Hour with Jim Lehrer, “Extended Interview: Mark Potts and Susan Defife.” Public Broadcasting Corporation, May 2005.

Norris, Pippa, "The Bridging and Bonding Role of Online Communities.” The Harvard International Journal of Press/Politics 7, 3 (Fall 2002): 3-13.

Parr, Barry, interview by author, transcript, telephone interview, 25 January 2006.

Poletti, Therese, “'Citizen Journalism' Effort for Palo Alto: D.C. Start-Up to Buy Bayosphere Web Site,” San Jose Mercury News, 18 April 2006.

Potts, Mark, interview by author, transcript, telephone interview, 17 January 2006.

PR Newswire, "YourHub.com Launches National Syndication.” [Accessed online 15 February 2006]: Accessed through Lexis-Nexus database.

PressThink, "Guest Writer Liz George of Baristanet Reviews Backfence.com Seven Months After Launch.” [2005]: http://journalism.nyu.edu/pubzone/weblogs/pressthink/2005/11/30/lz_bcfc.html.

Quinn, Stephen, The Fundamentals of Multimedia Reporting. New York: Focal Press, 2006.

Rafaeli, Sheizaf, Interactivity: From New Media to Communication. Beverly Hills, CA: Sage, 1988.

Romano, Allison, "Why Everybody is a Reporter: Citizen Journalists Go Mainstream.” Broadcasting \& Cable (22 August 2005).

Sabbagh, Dan, “Atrocity Brings Glimpse of the Citizen Journalist.” The Times of London (15 July 2005). 
Schild, Steven and Oren, Kim, "The Party Line Online: An Oligarchy of Opinion on a Public Affairs Listserv.” Journalism \& Communication Monographs 7, 1 (2005): $1-31$.

Schudson, Michael, The Power of News. Boston: Harvard University Press, 1995.

Schultz, Tanjev. "Interactive Options in Online Journalism: A Content Analysis of 100 U.S. Newspapers.” Journal of Computer-Mediated Communication 5, 1 (Spring 1999) [Accessed online 1 December 2004].

Schwartz, Jonathan, "Blogs Provide Raw Details from Disaster Scene.” The New York Times, 27 December 2004, A17.

Seelye, Katherine Q., “Why Newspapers are Betting on Audience Participation.” The New York Times, 4 July 2005, C1.

Shepherd, Gregory J., and Rothenbuhler, Eric W., Communication and Community. New Jersey: Lawrence Erlbaum, 2001.

Sulzberger, Arthur Jr., "Digital Decision Making at The New York Times.” The Harvard International Journal of Press/Politics 6, 2 (2001): 96-103.

Tönnies, Ferdinand, Community and Society: Gemeinschaft und Gesellschaft, ed. Charles P. Loomis, East Lansing: Michigan State University Press, 1957.

Weiner, Eric, “Citizens Journalists' at the Point of Breaking News,” National Public Radio (12 August 2005).

Wikipedia.org, “Bethesda,” [2006]: http://en.wikipedia,org/wiki/Bethesda\%2C_Maryland.

, “McLean,” [2006]: http://en.wikipedia.org/wiki/McLean\%2C_Virginia “Reston.” [2006]: http://en.wikipedia.org/wiki/Reston\%2C_Virginia

Wood, George S., Jr., and Judris, Juan C., Conversations on Community Theory. West Lafayette, Indiana: Purdue University Press, 2002. 